Preprints of the

Max Planck Institute for

Research on Collective Goods

Bonn 2012/7

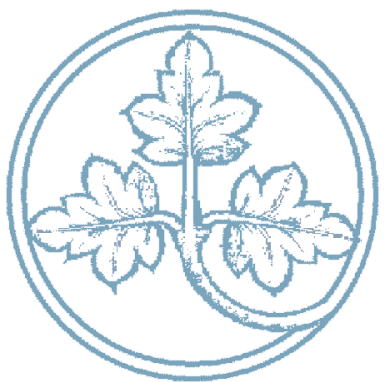

Assuring Adequate

Deterrence in Tort:

A Public Good Experiment

Theodore Eisenberg

Christoph Engel

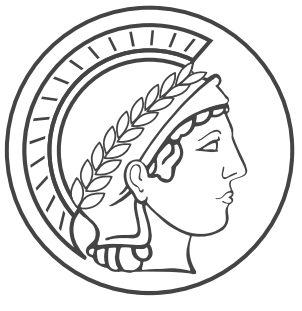




\section{Assuring Adequate Deterrence in Tort: A Public Good Experiment}

Theodore Eisenberg / Christoph Engel

April 2012 


\title{
Assuring Adequate Deterrence in Tort: A Public Good Experiment
}

\author{
Theodore Eisenberg and Christoph Engel ${ }^{*}$
}

\begin{abstract}
To explore damage rules' deterrent effect, we use a public good experiment to tailor allowable punishment to rules used in actual civil litigation. The experimental treatments are analogous to: (1) damages limited to harm to an individual litigant, (2) damages limited to harm to a group available in aggregate litigation, such as class actions, and (3) damages allowed beyond actual harm to victims, such as punitive damages. The treatment with damages limited to harm to an individual does not prevent the deterioration in cooperation over time commonly found in public good experiments without punishment or with too low punishment. In the class action damages treatment, cooperation is stable over time. In the damages-beyond-harm treatment, cooperation approaches the optimal level, but concerns of socially unjust punishment arise. In all treatments, a money maximising agent would be expected to completely freeride and make no contribution to the public good. Our results can thus not be explained by an incentive effect. Rather we find that social preferences interact with the severity of sanctions, even if imposing the sanction is not altruistic, but instead financially benefits the sanctioning authority. The results persist in a variation of the three treatments in which the player imposing damages has the option to not retain them for herself but to have them forfeited with no benefit to her. We can therefore rule out that the beneficial effect of sanctions hinges on the participants knowing that the player imposing sanctions cannot intend to enrich herself. The methodology we develop could be used to assess the social welfare benefit of many damages rules, such as treble damages in antitrust cases and caps on damages common in medical malpractice cases and punitive damages cases.
\end{abstract}

JEL: C73, K0, K4, K13

Keywords: Class actions, Deterrence, Tort, Damages, Public good experiment, Punitive damages

Eisenberg is Henry Allen Mark Professor of Law and Adjunct Professor of Statistical Sciences, Cornell University. Engel is Director, Max-Planck-Institute for Research on Collective Goods, Bonn, and a member of the Faculty of Law and Economics, University of Bonn. Helpful comments by Konstantinos Chatziathanasiou and Marc Jekel and the translation of the instructions into English by Brain Cooper are gratefully acknowledged. 


\section{Introduction}

Does damages liability promote socially desirable behavior? Reviews of tort law's effects reach mixed conclusions, with one finding tort law "somewhat successful" in deterring (Schwartz 1994: 443), but a recent experiment finding subjects' willingness to engage in risky behavior unaffected by the threat of potential tort liability (Cardi, Penfield et al. 2012). Empirical studies assess deterrence by comparing liability with non-liability, such as comparing alcohol-related motor vehicle fatalities across states that do or do not impose liability on commercial servers of alcoholic beverages (Sloan, Stout et al. 2000). Other studies compare the degree of available damages by assessing whether tort reforms such as noneconomic damage caps or higher evidentiary standards for punitive damages are associated with aggregated behavioral changes (for example Rubin and Shepherd 2006).

An attractive feature of such studies is that they investigate tort law in action. External validity is not an issue. Yet however carefully they are done, specifying models of outcomes, such as fatality rates or damages awards, is challenging. The analyst may be unsure about omitted variables and reverse causality is often a concern. She is at the mercy of naturally occurring variation, and cannot fine tune dependent and independent variables. Panel data usually are not available so one cannot address whether the same subjects continuously observed over time change their behavior in response to liability experience. For all of these reasons, experimental data are a useful complement. They are of course less "real" than observational data, but random assignment of experimental subjects makes modeling outcomes straightforward, removes identification problems, and observations over time enable evaluating the process leading to observed outcomes.

Public good experiments are particularly well suited to overcoming observational studies' limitations (for example Fehr and Gächter 2000). The experiments provide a continuous measure of one type of behavior society would want to deter, freeriding on others' efforts to provide public goods. Environmental damage can illustrate troublesome freeriding directly relating to tort (for example Hardin 1968). Clean water, clean air, or the proper disposal of waste, may all be modeled as public goods. Everyone benefits (there is no rivalry in consumption) and no one can be excluded (there is no property right). If others switch to a more costly alternative, those recklessly discharging pollutants free ride on their efforts.

In addition to assessing public good behavior, public good experiments' subjects repeatedly interact over time. This enables observing the dynamic individual-level process of behavior, followed by sanction, followed by possibly modified behavior, further possible sanction, and so on. Public good experiments therefore allow assessing whether participants change behavior in response to previous damages decisions. More generally, the experiments address whether subjects learn to adjust their behavior to the presence of the experimental institution, or risk that the institution becomes unsustainable. In a repeated game, one can also simultaneously investigate outcomes (how effective is the tort-like institution at deterring socially undesirable behavior?) and process (why does [does not] tort serve its stated purpose?). 
Studying deterrence via a public good experiment is also appealing because of such experiments often having implications for legal issues. Fehr and Gächter (2000), building on the Nobel Prizewinning work by Ostrom, Walker et al. (1992), demonstrated that people are willing to punish even when it is personally costly to them. Their findings may help explain both criminal and civil characteristics of legal systems. For example, this willingness may help explain acceptance of the death penalty despite "mixed and uncertain" empirical results about the penalty's deterrent effect (Frakes and Harding 2009: 452). The findings may also help explain the persistence of some countries' punitive damages practices, which allow civil wrongdoers to be punished beyond the harm caused to the individual suing. Use of public good experiments to explore the effects of legal rules is growing (Grechenig, Nicklisch et al. 2010; Engel and Kurschilgen 2011).

Studying tort deterrence in public good experiments is especially appropriate. Tort is frequently an alternative to other governance tools relating to public goods. A major advantage of tort governance over agency regulation is that private litigants have the power to initiate and directly benefit from deterrent activity. If litigants prevail, they are compensated for the damage they have suffered. This gives them a financial incentive to seek redress. If they are willing to pay part of the compensation to lawyers, they can afford professional advice, and thereby presumably increase both their chances of recovery and of achieving deterrence. Society need not pay for a regulatory agency or for an attorney general to achieve deterrence (Shavell 1984: 364) because deterrence is a side-benefit for society of self-interested action. And those suffering harm often have an informational advantage over public agencies (Shavell 1984: 359). Victims are unlikely to overlook socially disruptive behavior and often are best equipped to produce inculpating evidence. To the extent that victims are individuals, psychological effects give deterrence by tort additional clout. Many people strongly dislike being the sucker, and are willing to invest considerable effort to punish the wrongdoer (for example Fehr and Gächter 2000).

This paper is the first to use a public good experiment to study the deterrence and cooperationproducing effects of different civil damage regimes. To explore damage rules' influence on behavior, we tailor allowable sanctions, referred to herein as damages, to rules analogous to actual civil litigation rules. In each period of the multi-period experiment, a specified participant, the active player, may obtain damages from a targeted participant, subject to a different limitation in each treatment. The experiment's three treatments are analogous to: (1) damages to an individual litigant in the classical bipolar lawsuit, (2) damages to a group available in aggregate litigation such as class actions, and (3) damages beyond actual harm to victims, such as punitive damages. We are interested in which treatment yields the greatest contributions to the public good. In a full factorial design, we cross these three damages rule treatments with the presence or absence of the active player's additional option to destroy via forfeiture some or all of the targeted participant's period income, with no benefit to the active player, as in the case of societally imposed punishment. The maximum amount that the active player can cause to be forfeited equals the maximum damage amount that can be claimed in the respective treatments. This forfeit option is analogous to reporting misbehavior to the authorities, with the expectation of society-level pun- 
ishment being imposed, rather than suing in tort in the hope of obtaining individual-level economic benefit via damages for the plaintiff.

We find that substantial differences in contributions to the public good over time exist between the treatment with damages limited to harm to an individual, compared to damages expanded to harm to the group. In the individual damages (compensatory) treatment, cooperation deteriorates over time as subjects learn that damages are incomplete. In the group-harm (class action) damages treatment, cooperation is stable over time. In the damages-beyond-harm (punitive) treatment, contributions approach the optimal level, but concerns of socially unjust punishment arise. We also find that adding the forfeit option does not make a difference. Not only is the option rarely chosen. Its presence also does not change the respective damage rules' effects on public good behavior. At least in our experimental setting, contributions to the public good are thus unaffected by knowledge that punishment rather than damages may be the sanction for socially undesirable behavior. Participants are deterred by the risk, or by the experience, of losing income. They are indifferent to their ability to infer a selfish motive from a player's choice to enrich herself rather than to merely punish the participants.

\section{Background and Related Literature}

Our main intention is to contribute to the legal discourse about deterrence. Yet designing an experiment reasonably analogous to civil law institutions required design innovations that also contribute to the vast literature on public good experiments (Ledyard 1995; Zelmer 2003; Croson 2008; Chaudhuri 2011). We therefore briefly review relevant strands from the literature on both.

\subsection{Deterrence Literature}

A substantial literature concerning deterrence through civil actions exists. Gary Schwartz's thorough review of the tort deterrence literature concluded that, "between the economists' strong claim that tort law systematically deter and the critics' response that tort law rarely if ever deters lies an intermediate position: tort law, while not as effective as economic models suggest, may still be somewhat successful in achieving its stated deterrence goals" (Schwartz 1994: 443). A recent summary of the literature concluded that, "To date, no study has found that tort law serves as a comprehensive deterrent," some studies "have found limited evidence that tort acts as a weak deterrent with respect to certain behaviors" and that other studies, "have found no evidence of deterrence or even, in a few cases, a negative association - that certain tort rules are associated with an increase in related injuries" (Cardi, Penfield et al. 2012). Ours is the first incentivized test of deterrence using damages rules analogous to those in tort and class actions, under completely controlled, decontextualized conditions. 


\subsection{Public Good Experiment Background and Literature}

In the typical public good experimental design, subjects are given an endowment, usually 20 units of currency or tokens, and asked to contribute all or part of their endowment to the public good. The experiment's payoff structure is designed so that the group obtains a maximum return, in real currency, if all players contribute 100 percent of their endowment to the public good. Individually, however, each participant is best off not contributing at all. The contributions represent the degree of cooperation obtained. The pattern of contributions from the endowment is repeated over many periods to observe whether contributions change in response to earlier period experience. As summarized by Croson:

The results from this wide variety of experiments are quite robust. First, on average, contributions to the public good begin at about half the endowment of tokens. Second, there is considerable variation in the decisions of individuals. Third, those contributions reduce over time until the contributions in the final round are 10-20 per cent of the endowment.

This common pattern of deteriorating contributions to the public good over time is replicated in the baseline and compensatory treatment in this study, as shown in Figure 1 below.

The literature shows that the socially disruptive pattern ceases if participants are automatically punished or rewarded, depending on whether they have contributed more or less than the average of their group. Then contributions are stabilized at a high level (Falkinger, Fehr et al. 2000; Bracht, Figuieres et al. 2008) and the deterioration in cooperation over time can be avoided. ${ }^{1}$ If participants interpret the obligation to pay damages as a sanction, i.e., if the deterrence interpretation of torts gets it right, we should see a similar effect. We only do so in the class action and in the punitive treatments.

The main difference between our design and previous public good experiments is the redistribution mechanism that is analogous to that in civil actions. In our design, when a participant loses money, the participant entitled to impose that loss, the active player, gains money. If there is deterrence, it is inextricably tied to redistribution. This is not the case in the standard design where each group member is informed about all other group members' contributions, and is allowed to punish them, at a cost (Fehr and Gächter 2000; Fehr and Gächter 2002), not a benefit, to the punishing group member. In these experiments, each group member would be best off if other group members bear the cost of punishment, while she freerides on their enforcement efforts (Yamagishi 1986; Heckathorn 1989). Many experimental participants disregard this logic and

\footnotetext{
A provision point mechanism is also effective in increasing contributions. Under this scheme contributions are refunded, provided total contributions do not meet a predetermined schedule (Rondeau, Schulze et al. 1999). The mechanism outperforms a scheme where participants are just asked to make contributions (Rondeau, Poe et al. 2005). If each participant is able to subsidize other participants' contributions by ex ante pledging to reimburse a defined fraction of the contribution cost (which the authors call "compensation"), this also helps raise contributions, but less than the tax subsidy scheme of the former mechanism (Bracht, Figuieres et al. 2008). If participants are given the opportunity to ex post reward other participants, this has about the same effect as a punishment opportunity. If both options are combined, contributions are even higher (Sefton, Shupp et al. 2007).
} 
punish freeriders (Fehr and Gächter 2000; Fehr and Gächter 2002; Fehr and Fischbacher 2004) even though the participants must pay to punish. The design of the those experimental games assures that money maximizing agents would not punish, even if they foresee that taming freeriding in the long run is good for everybody.

The difference between damages, in which a participant retains the amounts taken from other players, and punishment, in which the player does not, may have two opposing effects. On the one hand, the active player now has an incentive to punish, even if we only consider the stage game, and even if we assume that she does not hold social preferences. This reduces the behavioral uncertainty. Those contributing little have more reason to expect a sanction. This should improve contributions. A socially beneficial effect might also result from the money participants must pay not being lost, but benefitting the active player. This may give the mechanism additional legitimacy since the act of sanctioning may be perceived to be more fair. Since the money is not lost, participants who care about efficiency (cf. Engelmann and Strobel 2004; Page, Putterman et al. 2005) may be more inclined to adjust their behavior to the group norm in the future. On the other hand, sanctioning now is selfish. If participants care about motives, this might lead to deterioration of contributions.

\section{Predictions}

As noted, our focus is on public good contributions as influenced by varying damages rules. We explore whether varying damages rules, meant to be analogous to damages principles applicable in cases, reduce the externalities that a noncooperator inflicts on the group and avoids the deteriorating contribution pattern that is common in public good experiments. In particular, do damages rules that promote recovering the full harm caused by a noncooperator affect contributions over time?

In a standard symmetric linear public good without punishment, all group members contributing nothing in all periods prescribes the unique Nash equilibrium. Agents holding standard preferences never use the punishment option, which is correctly anticipated by other such agents. Therefore adding punishment does not change the prediction. In the Appendix we show that the right to obtain damages does not change this prediction, provided that all agents hold standard preferences and this is common knowledge. This leads to

Prediction 1: In all treatments all participants will contribute nothing to the public good.

Despite the game theoretic prediction, previous experimental results lead us not to expect this outcome. It is well established that, in a standard public good experiment without sanctions, mean contributions to the public good start near the middle of a subject's endowment and decay over time. Yet this changes if freeriders have reason to fear punishment. We have no reason to expect that the right to claim damages rather than to impose costly punishment leads to even lower contributions. Yet, depending on driving forces, contributions in our treatments should differ from a baseline with no right to claim damages in different but unidirectional ways. A 
first possibility is a vigilance effect that is expected to reduce extensive freeriding. In all treatments, freeriders come under public scrutiny, and they run some risk of being sanctioned. This leads to

Prediction 2: In all treatments, contributions will be higher than in the baseline. There are no significant differences between treatments, either with respect to the level of contributions or with respect to their development over time.

The absence of differences is of course not what the deterrence explanation of tort would predict. It is axiomatic in law and economics that some level of damages will induce potential injurers to adjust their level of care, but that underdeterrence should result from insufficient levels of damages (Shavell 2007: 144). Similarly, damages for breach of contract are predicted to affect incentives to perform contracts (Hermalin, Katz et al. 2007: 102). But recall that, in our experiment, theoretically no freerider should be deterred, not even in the treatments where her entire period income is in peril. A money maximizing participant is always best off keeping her entire endowment for herself. Yet the experimental literature on public goods with punishment shows that contributions are sensitive to the severity of punishment. The more income one punishment point destroys, the higher average contributions, and the more positive the trend over time (Nikiforakis and Normann 2008). One possibility for our participants is to translate the three damage rules into an expected value of receiving a sanction, and to be sensitive to the size of the risk of losing money. We then would expect a marginal reaction. This yields

Prediction 3: Contributions will be lowest in the baseline, somewhat higher if the active player may claim her own damages, yet higher if she may claim everybody's damage, and highest if damages are only limited by period income. The higher the amount a passive player must possibly pay, the more positive the development of mean contributions over time. Adding the forfeit option to punish without the active player collecting damages is immaterial.

In contrast, participants might consider unlimited sanctions outrageous, and exhibit reactance (Brehm 1966; Brehm and Brehm 1981). They might be unwilling to change behavior in response to sanctions that are patently unjust. Earlier studies have demonstrated that some, but not all people exhibit reactance. That leads to

Prediction 4: Contributions if the active player may claim everybody's damage, and contributions if damages are only limited by period income will not be distinguishable.

Finally earlier experiments have shown that the willingness to cooperate despite the fact that participants face a dilemma can at least partly be explained by a reaction to perceived or hypothesized intentions (Charness and Rabin 2002; Falk, Fehr et al. 2008). Adding the option to merely punish players makes it possible for active players to signal the intention of not wanting to enrich themselves. If they forego the option, participants know that redistribution has at least been a concomitant, if not the only, motive. 
Prediction 5: If given the opportunity to punish, rather than claim damages, active participants will frequently use the option. If they do, more cooperation will emerge than in the parallel treatment without this option. If they do not, less cooperation will result.

\section{Design and Conduct of the Experiment}

The experiment used Experimental Currency Units (ECUs). Participants were informed that the total ECUs earned would be converted to Euros at the rate of $1 \mathrm{ECU}=0.01 €$, and that they would be immediately paid in cash at the end of the experiment. At the beginning of the experiment the participants were randomly divided into groups of four. As is common in public good experiments, the composition of each group remained the same throughout the experiment (partner design) and the experiment lasted 30 periods.

Each period was divided into two stages. In the first stage, at the beginning of each of the 30 periods, each participant received 20 ECUs, commonly referred to in public good experiments as the "endowment." Participants decided how to use their endowments. They had to decide how many of the 20 ECUs to contribute to a project (from 0 to 20) and how many of them to keep. Once all the members of a group had decided on their contributions to the project, they were informed about each participant's contribution. Each participant's payoff in a period used the following formula, common to public good experiments:

\begin{tabular}{|l|l|l|l|}
\hline $\begin{array}{l}\text { Income to } \\
\text { participant }\end{array} \quad$ Endowment of 20 & $\begin{array}{l}\text { Participant } \\
\text { contribution to the pro- } \\
\text { ject }\end{array}$ & $\begin{array}{l}0.4 * \text { Total } \\
\text { contributions to the } \\
\text { project }\end{array}$ \\
\hline
\end{tabular}

Thus, participant first stage income consisted of (1) the ECUs that participant kept by not contributing (endowment - contribution), plus (2) the income from the project, which equaled 40 percent of the four-person group's total contribution.

Each group member's income from the project was calculated the same way and thus each group member received the same income from the project. For example, if the sum of the contributions of all group members was 60 ECUs, each member of the group received an income from the project for that period of: $0.4 * 60=24$ ECUs. If the total contribution to the project was 9 ECUs, then each member of the group received an income of: $0.4 * 9=3.6$ ECUs from the project. From a social welfare perspective, total profit of participants is maximized if all group members contribute their entire endowment. In that case, retained noncontributed ECUs equal zero, total contributions to the project equal 80 , and each member's income equals $0.4 * 80=32$ for total social welfare of 128. If one member retained her ECUs and all others contributed 20, that noncontributing member would have first stage income of 20 plus $0.4 * 60$, or 44 . But the other members would only have first stage income of zero plus $0.4 * 60$, or 24 . Total social welfare would equal 44 plus $3 * 24$ or 112 .

As is required for there to be a public good problem in a linear game, the return from the public good (making a contribution) to the individual is lower than the return from the private good (re- 
taining the endowment) because $0.4<1$. Individuals do not have an individual incentive to contribute and the dominant individual strategy equilibrium in the stage game is thus to contribute zero. But the social benefit from contributing to the public good is greater than the social cost because four players benefit from each contribution and only one suffers the cost of paying part of the player's endowment $(0.4 * 4=1.6>1)$. Thus contributing toward the public good is socially efficient (Croson 2008).

In the second stage, participants were informed how much each group member contributed individually to the project at the first stage. In each period, one group member was randomly selected to act in the second stage and is referred to as "the active player." Only the active player was allowed to react to the information regarding the contributions of the other three group members. This feature of the design is meant to reflect that, in the field, frequently victims do not take the tort feasor to court, a result found in actual practice (for example Hensler, Marquis et al. 1991)and in a public good experiment (Eisenberg 2007; Güth, Kliemt et al. 2007). This is particularly frequent in the case we are specifically interested in, where harm is diffuse. The active player could react by choosing from which other group member(s) to take ECUs. The second stage varied depending on which of three treatments was used, which we now describe.

\subsection{Compensatory Damages Treatment: Damages Limited to Harm to the Active Player}

The first treatment allowed the active player to impose damages that are analogous to damages in a standard bipolar lawsuit. Such lawsuits involve a single plaintiff suing a single defendant. The limit on damages in such suits is the amount of harm the defendant caused the plaintiff. Our first treatment is analogous to this civil damages scenario because the treatment limited the amount of damages that the active player could impose on other players to the harm that the punished player caused to the person imposing damages.

Thus, in the first treatment, the active player could take at most an amount to equalize the difference between what the active player received and what she would have received in the period if the punished players had contributed as much to the project as the active player did. For example, assume that the active player in the second stage had contributed 15 ECUs and that another member of the active player's group had contributed 5 ECUs. The remaining two members each contributed 10. Therefore the payoff to the active player for this period is computed as: 20 [endowment] -15 [contribution from endowment] $+.4 *(15+10+10+5)$ [income from project] $=21$. Had all other group members also contributed 15, total contributions to the project in the period would have been $4 * 15=60$, and the active player would have earned 29 ECUs. The active player would thus have earned 8 more ECUs. She is free to choose from whom she wants to take money, but may not take more from any other player than that player has contributed to the 8 ECU difference. Had the fourth player contributed 15 instead of 5 ECUs, the active player would have earned 4 more ECUs, which is the maximum she can take from that player. Similar calcula- 
tions show that she can at most take 2 ECUs from the remaining two passive players. In the experiment, these limits appear on the decision screen of the active player.

In the extreme case, the active player contributed 20 and the punished players all contributed 0. Then the harm to the active player caused by each player is $0.4 * 20=8$. If all three non-active players in the group contributed zero, she may take 8 from the other players. Her total income, including compensation for the noncooperative behavior of the players, is 32 . If the randomly selected active player contributed less of her endowment than the other players, no damages could be imposed in that period of the experiment for that group.

\subsection{Class Action Treatment: Damages Limited to Harm to the Group}

Defendants often damage more than one person, as in the case of unsafe drugs, oil spills, nuclear accidents, questionable financial practices, and other misbehaviors. In some legal orders, legislators react by providing some form of aggregate litigation such as a class action, consolidation of lawsuits, or, in the United States, a multi-district forum. In a class action, a procedural device prominent in at least the United States, the Netherlands, Australia, and Israel (Plato-Shanar 2007), one or a few plaintiffs sue as representatives on behalf of all those harmed by a defendant's behavior.

Such aggregate litigation addresses a weakness in relying on tort to adequately deter. The harm from socially undesirable behavior relating to a public good can be diffuse. Many may suffer if a single individual misbehaves and total social harm may be pronounced. But individual harm frequently is minuscule, leading to the frequently observed decision not to seek redress. The more victims the lower the probability that all victims will find it worthwhile to sue the tortfeasor. To the extent this is correctly anticipated, or experienced, by the tortfeasor, tort deterrence is suboptimal. In countries with the American rule on the assignment of litigation costs, the problem may be exacerbated. If an individual victim's expected damages are too small, she will be unable to obtain professional advice, which gives the tortfeasor an advantage and underdeterrence is even more likely. In practice, in the U.S., the victim often does not seek a lawyer; instead the lawyer seeks the victim and offers representation on a contingency fee basis. In principle, this promotes deterrence. But if the expected damage is too small, too little deterrence is very likely.

The second treatment explored the effect of aggregate remedial devices such as class actions. It is analogous to a class action in that the active player was allowed to claim redress for the total harm the punished player caused to the group, rather than limiting damages to the harm caused to the active player herself. Specifically, the active player could take at most the difference between the actual income of all group members and the income they would have had, had all contributed as much as the active player did. The active player's capacity to impose damages on a lower contributing player is also limited by the amount the punished player earned in the period. 
We have allowed the active player to retain all damages in the class action treatment for a substantive and for an experimental reason. In actual class actions the plaintiff represents the class and damages are distributed to other class members at the end of the law suit. In our design the active player keeps the entire amount. Yet the dependent variable of interest is not what active players claim, but how passive players (and the entire group, for that matter) react. Pragmatically, our solution makes it possible to have only one of four group members be given the right to become active. If damages had to be distributed to other group members, we would have had more than one change between the compensatory and the class action treatments, and would have lost the opportunity to identify the cause of changes in contribution behavior. Substantively, it reflects a situation that is frequent in the U.S. Whether a case is brought chiefly depends on whether an attorney selects the case and brings it on a contingent fee basis. If class action status is obtained, the attorney hopes to collect a substantially higher fee. The attorney incentive is to obtain a substantial fraction of the class recovery as a fee, which they regularly succeed in doing (for example Eisenberg and Miller 2010).

To illustrate the second treatment, consider the same example as before. The active player contributed 15 ECUs in the first stage. Another member of the active player's group contributed 5. The remaining two members each contributed 10. Therefore the active player's payoff is 20 [endowment] -15 [contribution from endowment] $+.4 *(15+10+10+5)$ [income from project $]=$ 21. By analogous calculations, the payoff to the remaining group members is 26,26 , and 31 . Therefore the total payoff to the group is 104 . Had all group members contributed 15 , total contributions to the project would have been $4 * 15=60$, and each would have earned 29 . The total payoff of the group would then have been 116 . Hence the limit on what the active player may take from the punished players is $116-104=12$. The active player is free how to distribute the damages among the passive players, provided the amount taken does not exceed a player's period income.

\subsection{Punitive Damages Treatment: Damages Limited by Punishee's Income}

The third treatment did not limit damages to the harm the noncooperator caused to an individual or to the group. The only limit on damages was the punished player's income received in the period, irrespective of the level of harm the player caused. This treatment does not correspond as precisely to a category of damages as do the damages in the first two treatments. It corresponds in some respects to punitive damages (and we refer to it as the punitive treatment), which are not limited to the harm caused, in legal systems allowing them. Such damages are associated with the United States, but other countries, such as England and Ireland, allow them in limited circumstances (Rookes v. Barnard 1964; AB v. South West Water Services 1993; Bradford Metropolitan City Council v. Arora 1991; Conway v. Irish National Teachers Organisation 1991). The severance of damages levels from actual harm caused is also analogous to damages allowed in many countries, including Germany, as "aggravated damages" (Law Reform Commission of Ireland 1998), based on the mental distress or suffering of the plaintiff or the defendant's exceptional misconduct (Alexander v. Home Office 1988). 
Our punitive treatment differs from standard notions of punitive damages in that it requires no misbehavior by the punishee. The active player is free to take all of the punishee's income regardless of whether the punishee caused harm. We have chosen this design to put to the most radical test the claim that punitive damages serve no deterrent function. Professor Viscusi claimed, for example, that "there is no deterrent benefit that justifies the chaos and economic disruption inflicted by punitive damages" (Viscusi 1998). ${ }^{2}$ We wanted to see whether unlimited damages serve a deterrent function, despite the obvious injustice of not tying the punishment to misbehavior.

\subsection{The Forfeiture Variation}

For each of the three treatments, we introduced another variation. We thus have a $3 \times 2$ factorial design. As we have described, in the first set of three treatments, the active player retains the damages that the player assesses. In the second set of three treatments, the active player may choose not to retain the damages imposed; they are simply forfeited. This helps explore the extent to which the pattern of damages imposed over time is attributable to the active player's benefit of retaining damages or to the desire to express disapproval of low contributors ' behavior, regardless of benefit to the active player. Through the additional option, active members can signal their intention to discipline the group, rather than enriching themselves. We can investigate whether the beneficial effect of imposing harm on free riders hinges on the active player's intentions.

\subsection{Procedures}

Regardless of the treatment or the forfeiture variation, in each period, each group member was randomly assigned a number between one and four. Group members were thus not identified across periods. They therefore did not know which group members had been entitled to impose damages in earlier periods. A participant only learned whether income had been shifted, and how much, if the active player had taken some of the participant's period income.

The six treatments were conducted in July of 2011 in Bonn, Germany using z-Tree software developed by Fischbacher (2007). The data for the one comparison with a baseline without a punishment / damage option is taken from a different experiment run with exactly the same protocol, exactly the same program, in exactly the same lab in February 2010. Participants were invited using the software ORSEE (Greiner 2004). A total of 300 students of different majors participated in the experiment, mean age 23.83 years, $56.90 \%$ female. The data were analyzed using Stata version 12. Table 1 shows the design and participation levels for the experiment. 
Table 1. Experimental Design and Participation Levels

\begin{tabular}{|l|c|c|c|c|}
\hline $\begin{array}{l}\text { Treatment=varying limits on } \\
\text { damages in the second stage }\end{array}$ & Active player option & $\begin{array}{c}\text { Number of } \\
\text { participants }\end{array}$ & $\begin{array}{c}\text { Number of } 4 \\
\text { person groups }\end{array}$ & $\begin{array}{c}\text { Number of } \\
\text { observations }\end{array}$ \\
\hline Baseline: no damages & N/A & 20 & 5 & 600 \\
\hline Compensation of active player & Retain damages & 48 & 12 & 1440 \\
\hline Class action damages & Retain damages & 48 & 12 & 1440 \\
\hline Punitive damages & Retain damages & 48 & 12 & 1440 \\
\hline Compensation of active player & Retain or forfeit damages & 44 & 11 & 1320 \\
\hline Class action damages & Retain or forfeit damages & 48 & 12 & 1440 \\
\hline Punitive damages & Retain or forfeit damages & 44 & 11 & 1300 \\
\hline
\end{tabular}

Note: In two treatments, one group of 4 could not be filled since not enough invited participants showed up. $\mathrm{N} / \mathrm{A}=$ not applicable.

\section{Results}

Table 2 reports summary statistics. The first column shows the six treatments plus a baseline condition in which no damages could be assessed. Note that in the compensation and class action treatments, the mean assessed damages were only about one ECU per player. This is common in such experiments (for example Nikiforakis, Normann et al. 2010: 638). It is in part because the active player could only take damages from those who contributed less of their endowment than did the active player and those damages were capped by the treatment rule. The active player otherwise eligible to impose damages could also choose not to do so. In the compensatory and class action treatments in which the active player was entitled to impose damages, nonzero damages were imposed on 31 percent and 20 percent of the nonactive player participants, respectively. The modal damages amount in these treatments was thus zero. In the punitive treatment, nonzero damages were imposed on 89 percent of the nonactive player participants. Similar percentages were punished in the treatments with a forfeit-damages option.

Table 2. Descriptive Statistics for the Six Treatments

\begin{tabular}{|l|l|c|c|c|c|}
\hline $\begin{array}{l}\text { Treatment=varying limits on } \\
\text { damages in the second stage }\end{array}$ & $\begin{array}{c}\text { Active player } \\
\text { option }\end{array}$ & $\begin{array}{c}\text { Contribution } \\
\text { by all play- } \\
\text { ers }\end{array}$ & $\begin{array}{c}\text { Damages } \\
\text { assessed by } \\
\text { active player }\end{array}$ & $\begin{array}{c}\text { Project } \\
\text { income, } \\
\text { all periods }\end{array}$ & $\begin{array}{c}\text { Project in- } \\
\text { come, last } \\
10 \text { periods }\end{array}$ \\
\hline Baseline: no damages & N/A & 8.1 & N/A & 24.8 & 23.5 \\
\hline Compensation of active player & Retain damages & 10.9 & 1.1 & 43.5 & 34.6 \\
\hline Class action damages & Retain damages & 10.6 & 1.0 & 42.4 & 40.4 \\
\hline Punitive damages & Retain damages & 13.9 & 22.6 & 55.5 & 57.2 \\
\hline Compensation of active player & $\begin{array}{c}\text { Retain or forfeit } \\
\text { damages }\end{array}$ & 10.5 & 1.1 & 42.1 & 38.0 \\
\hline Class action damages & $\begin{array}{c}\text { Retain or forfeit } \\
\text { damages }\end{array}$ & 11.1 & 1.1 & 44.4 & 38.3 \\
\hline Punitive damages & $\begin{array}{c}\text { Retain or forfeit } \\
\text { damages }\end{array}$ & 13.1 & 21.8 & 52.4 & 62.4 \\
\hline
\end{tabular}

Note. All numerical entries are average ECUs at the individual participant level. Each treatment was run for 30 periods. The damages assessed column computes average damages without including the active player, who is immune from damages liability. $\mathrm{N} / \mathrm{A}=$ not applicable. 


\subsection{Compensatory Damages Treatment}

As shown above, from a social welfare perspective, each member contributing her entire endowment maximizes group profit. If a group member contributes little or nothing, the remaining group members earn less than the potential maximum. If enough group members contribute small amounts, the more selfless group members earn less than their endowment. The compensatory treatment seeks to compensate a higher-contributing group member at the expense of lowercontributing members. The line labeled "compensatory treatment" in Figure 1 shows mean contributions for the first treatment. The pattern exhibits the classic public good experiment decay in cooperation over time with no leveling off by the end of the experiment in the thirtieth period. Over time, the tension between private gain and public good tends towards resolution in favor of private gain. Unsurprisingly, we reject Prediction 1, which forecast zero contributions throughout.

We attribute the deterioration in cooperation to the first treatment's incomplete compensation mechanism. Since in each period only one participant may claim damages, redress is only complete if the active participant had contributed more ECUs than all other participants. This is because the active player can only take as damages amounts determined by what the active player contributed. The punished player may have inflicted greater harm on the group if higher contributors were not randomly selected as the active player. The compensation rule also creates an asymmetry: only the participant with the right to claim damages is compensated, while the remaining group members are not, irrespective of the size of their contributions. Due to this limitation, the low contributors who paid compensation may have caused harm to other members of the group that is not internalized to the low contributors. In a forward looking perspective, this causes deterrence to be incomplete.

We first compare contributions in the compensatory treatment with contributions in the baseline (labelled "VCM", or voluntary contribution mechanism, in Figure 1), in which no claim for damages is allowed. Participants are simply asked to contribute over time without the effects of second stage punishment. The theoretical equilibrium is zero contributions, for reasons similar to those discussed above. The baseline reasonably reproduces the common public good experiment outcome of deteriorating contributions over time (Croson 2008: Figure 1).

As Figure 1 shows, despite the limitations on damages in our compensatory treatment, contributions are higher in the compensatory treatment than in the baseline from period three on. A declining level of contributions over time exists for both the compensatory treatment and the baseline. But the decay is less steep in the compensatory treatment than in the baseline. In a nonparametric test, the difference in levels is insignificant (Mann-Whitney, $\mathrm{N}=17, \mathrm{p}=.3428$ ), ${ }^{3}$ while slopes are significantly different (Mann-Whitney over means of first differences, $\mathrm{N}=17$, $\mathrm{p}=.0131)$. 


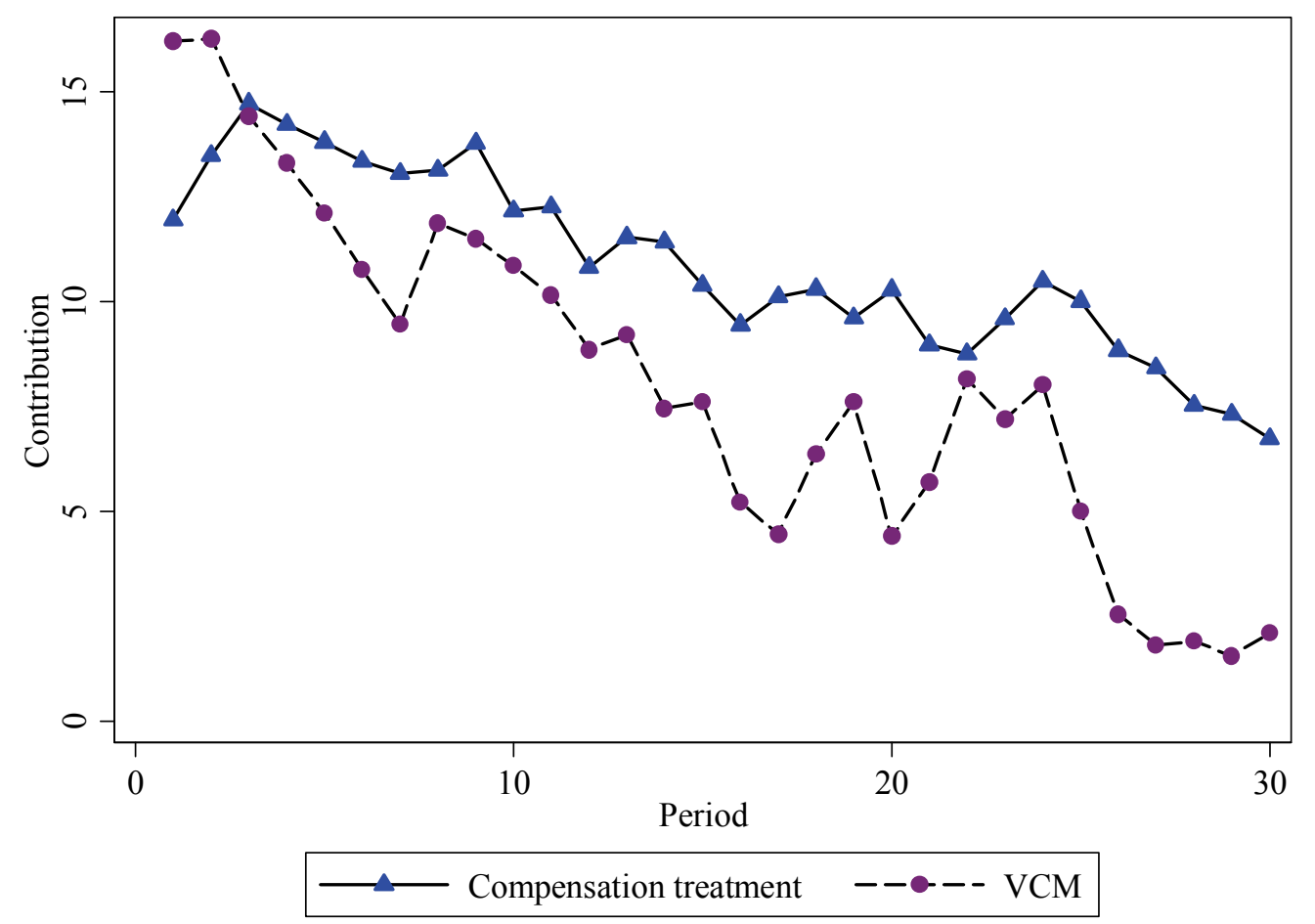

Figure 1. Treatment effect: baseline vs. compensatory treatment

To more fully assess the patterns in Figure 1, we employ regression models. The data raise methodological issues. First, in both treatments, a substantial fraction of participants contributes zero from their endowment, and another sizeable fraction contributes their entire endowments of 20 ECUs. The distribution of contributions in all treatments is in the Appendix. The data cluster at contributions of both zero and 20, for which we adjust using Tobit models ${ }^{4}$ that often are used as a primary or secondary regression methodology in analyzing public good experimental data (for example Fehr and Gächter 2000: 991; Gächter and Renner 2010: 374 f.). Second, assumptions of independence of observations that underlie standard error computations are not satisfied. Participants make choices in 30 consecutive periods, leading to non-independence of observations over time. And, as described above, participants remain in the same group of four for the entire duration of the experiment, further violating the standard independence assumption.

Ideally we therefore would want to estimate a mixed effects model, with an error term for the group, another error term for the individuals nested in a group, and residual error. Unfortunately, for Tobit models no such estimator is available. We address the problem of non-independence in two ways. First, we exploit the fact that one of us has shown experimentally elsewhere (in an experiment that had the same parameters as this experiment) that in linear public goods experiments a group's average contributions in the first period are a useful measure of group idiosyncrasy. ${ }^{5}$ The mean contribution in this period is a good predictor of contributions in later periods

4 For concern about using Tobit models in the presence of actual (not truly censored) zero values, see (Choi and Eisenberg 2010: 532 n. 524). This concern, and the dependent variable's failure to satisfy the Tobit model's assumed truncated normal distribution, led us to employ as checks the other models we refer to.

5 This correlation raises a question of serial correlation in the data, which could render standard errors inaccurate. To assess this, we also used (1) Prais-Winsten models with standard errors clustered on individual and 
(Beckenkamp, Engel et al. 2009). We therefore can account for group characteristics using a factor we are able to observe. For parametric estimation we therefore use a random effects Tobit model, with period and individual accounted for, and add the mean contribution, in each group, in the first period, as a control variable. We only model contributions from the second period on, to avoid endogeneity. Second, we use multilevel models that account for the non-independence of observations of the same individuals and groups by using random intercepts. Such regression models also are frequently used in analyzing public good experiment data (for example Gächter and Renner 2010: 374f.; Nikiforakis, Normann et al. 2010: 648; Janssen, Anderies et al. 2011: 562) and they do not require omitting first period results. We report both the Tobit and multilevel model results. ${ }^{6}$

In each model in Table 3, the dependent variable is a participant's contribution to the public project. Compensation is a dummy explanatory variable to distinguish between the compensatory treatment and the baseline. Average contribution, $1^{\text {st }}$ period, is each group's average contribution in the first period of the experiment. Period is a variable to track periods 2 to 30 in models (1)-(3) and periods 1 to 30 in models (4)-(6).

The first two models in Table 3 show a significant treatment effect. Contributions are substantially higher if participants may claim compensation than if no sanctions exist for low contributions. But Figure 1 suggests a difference in slope as well as in intercept for compensatory treatment vs. baseline. Model 3 adds an interaction term equal to the product of the compensation dummy variable and period. It is highly significant and positive, suggesting that, compared to the baseline, the compensatory treatment leads to slower deterioration in cooperation. The beneficial effect of giving one participant the right to claim damages becomes more pronounced the more participants have experience with this institution. In model (3) and in the multilevel models, the compensatory treatment variable is insignificant, but the interaction term remains highly significant. The results in models (4) to (6) are consistent with the nonparametric results noted above. So a robust finding is that the decline in cooperation in the compensatory treatment is less pronounced than in the baseline, but that the trend over time is nevertheless towards complete noncooperation. We thus have weak, provisional support for either Prediction 2 (all treatments outperform the baseline) or Prediction 3 (the more severe the threat of sanctions, the higher mean contributions, and the less contributions decay over time).

then group to address concerns about serial correlation in the dependent variable, and (2) panel data models that account for serial correlation (xtregar in Stata version 12). All key results emerged again in those models.

6 As a check on the results in Table 3, we used a similar random effects interval regression panel data model since the dependent variable tends to cluster at values of $0,5,10,15$, and 20 , as shown by the distributions in the Appendix. The core result of Table 3, that cooperation decays but does so less quickly for the compensatory treatment, remained significant. 
Table 3. Treatment Difference: Baseline (no damages) and Compensation Damages

\begin{tabular}{|c|c|c|c|c|c|c|}
\hline & Model 1 & Model 2 & Model 3 & Model 4 & Model 5 & Model 6 \\
\hline & \multicolumn{3}{|c|}{ Tobit models } & \multicolumn{3}{|c|}{ Multilevel models } \\
\hline & \multicolumn{6}{|c|}{ Dependent variable=amount contributed to the public good } \\
\hline Compensation dummy & $10.520 * *$ & $10.341 * *$ & 3.432 & 2.812 & 2.812 & -0.433 \\
\hline Ave. contrib., $1^{\text {st }}$ period & $0.808^{*}$ & $0.793^{*}$ & $0.781^{*}$ & & & \\
\hline Period & & $-0.589 * * *$ & $-0.911 * * *$ & & $-0.291 * * *$ & $-0.439 * * *$ \\
\hline Compensation * period & & & $0.446^{* * *}$ & & & $0.209 * * *$ \\
\hline Constant & -7.946 & 1.637 & 6.683 & $8.062 * * *$ & $12.576^{* * *}$ & 14.866 \\
\hline Number of observations & 1972 & 1972 & 1972 & 2040 & 2040 & 2040 \\
\hline Number of periods & 29 & 29 & 29 & 30 & 30 & 30 \\
\hline Number of individuals & 68 & 68 & 68 & 68 & 68 & 68 \\
\hline Number of groups & 17 & 17 & 17 & 17 & 17 & 17 \\
\hline left censored & 544 & 544 & 544 & & & \\
\hline right censored & 523 & 523 & 523 & & & \\
\hline$\sigma$ (individual) & & & & $2.787 * * *$ & $2.826^{* * *}$ & $2.830 * * *$ \\
\hline$\sigma$ (group) & & & & $3.580 * * *$ & $3.580 * * *$ & $3.580 * * *$ \\
\hline $\mathrm{p}$ model & 0.0033 & $<0.001$ & $<0.001$ & $<0.001$ & $<0.001$ & $<0.001$ \\
\hline
\end{tabular}

Note. Models (1)-(3) report random effects Tobit models of the amount contributed to the public good by each participant in each period, with censoring at 0 and 20 ECUs. Models (4)-(6) are multilevel models that include random intercepts for group and individual. The models include data only from the baseline and compensatory treatment. The marginal effects of compensation are identical with coefficients. ${ }^{* * *} \mathrm{p}<.001, * * \mathrm{p}<.01,{ }^{*} \mathrm{p}<.05$.

To explain the compensatory treatment's effect, we analyze the factors associated with changing contributions over time. ${ }^{7}$ The change over time is represented by the difference between the contribution in the current period and the contribution in the prior period and we model these first differences. The characteristics used as explanatory variables are a dummy variable for whether the participant was required to pay damages in the prior period, the participant's profit in the prior period, and the participant's accumulated profit in all prior periods.

In the compensatory treatment, contributions increased by an average of 2.8 ECUs when the participant had been required to pay damages in the prior period $(\mathrm{N}=292)$ and decreased by an average of 1.0 ECU when the participant did not pay damages $(\mathrm{N}=1100)$. The difference is highly statistically significant $(\mathrm{p}<0.001)$ using either a t-test or a Mann-Whitney test or a multilevel model that accounts for the nonindependence of observations across groups and individuals. No punishment occurred in the baseline so this relationship cannot be assessed. Figure 2 shows the relation between the change in contributions and prior period profit for the compensatory treatment $(2 \mathrm{~A}$ and $2 \mathrm{~B}$ ) and for the baseline (2C and 2D). Each subfigure displays a scatterplot and the kernel smoothed line that best fits the data. The association between accumulated profit and change in contribution is barely positive, whereas the association between prior period profit and change in contribution is substantial and positive.

7 As is standard in the experimental literature, strictly speaking our investigation of explanatory factors is exploratory. 

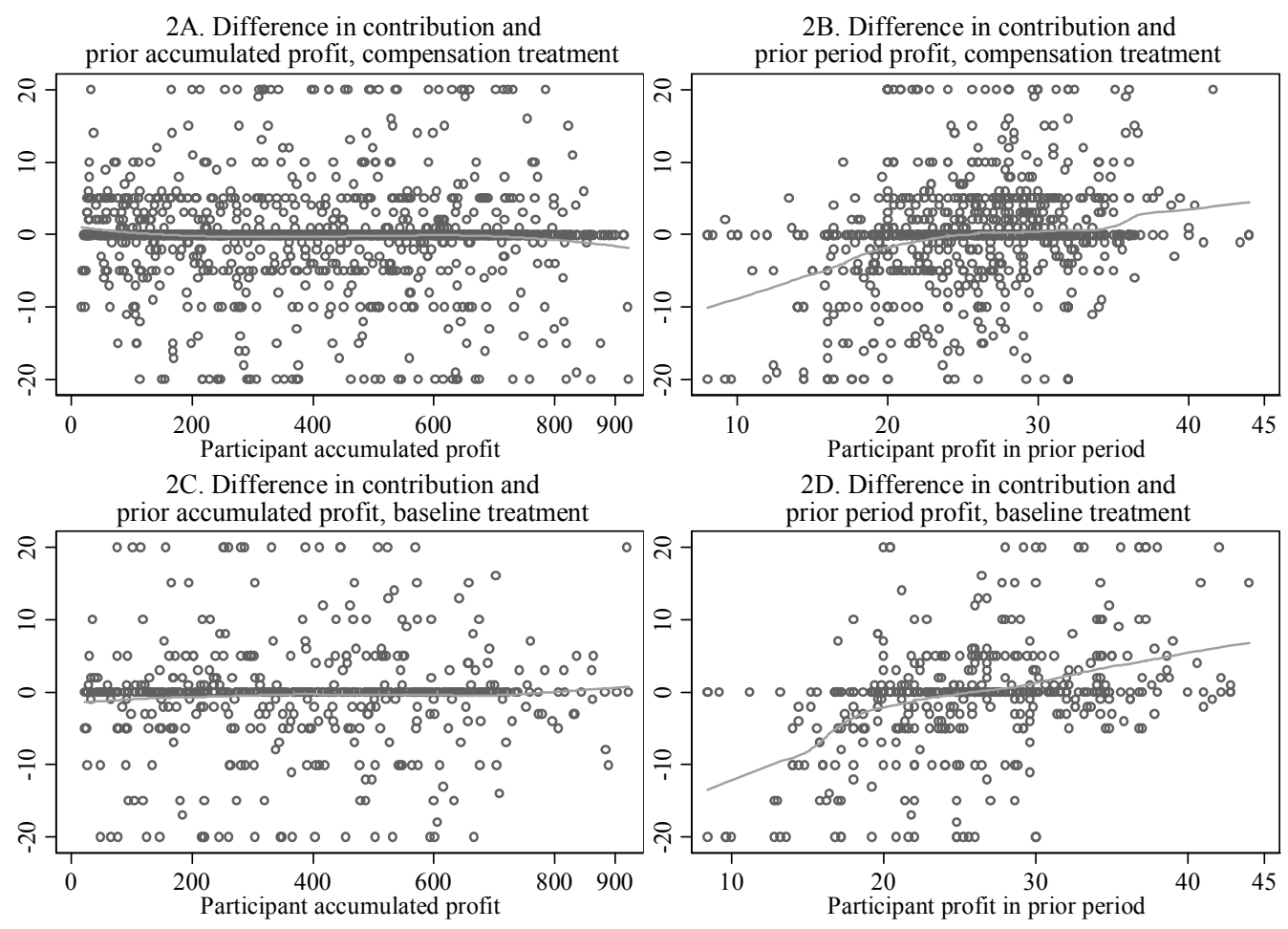

2B. Difference in contribution and
prior period profit, compensation treatment

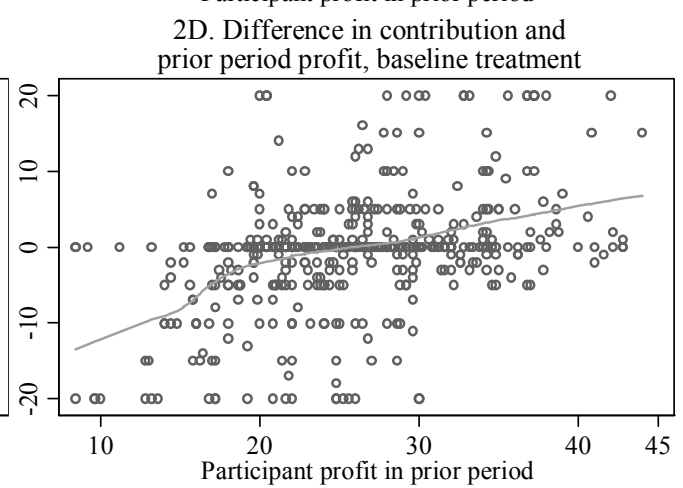

Figure 2. Change in contribution and prior profit

Table 4 combines the influences on contribution dynamics in regression models. The differenced dependent variable is more continuous than the contributions themselves so we estimate a linear random effects model with prior period profits and sanctions as the explanatory variables. ${ }^{8}$

Model 1 of Table 4 compares the baseline and the compensatory treatment. The treatment main effect shows that contribution dynamics are more positive when a participant can claim compensation. Note, however, that the sum of the constant and the treatment main effect is still pronouncedly negative, implying that even with the compensation scheme contributions decay over time. The beneficial effect of having earned a high profit in the previous period is less pronounced in the compensatory treatment than in the baseline. This suggests that the beneficial effect of the treatment results from the availability of the institution in the abstract, not from the individual experiences of participants with the institution in action. Total past profit not only has no beneficial effect; conditional on profit from the past period, it even has a significant negative effect. This suggests that participants do not adopt a longterm perspective but rather react to immediate experiences. Since no sanction is available in the baseline, model 2 examines the compensatory treatment in isolation. This model shows that the effect of sanctions rests in significant part on individual experiences. Those who were obliged to pay compensation increase their contributions in the subsequent period by more than one point for each point they had to pay to the active group member. 
Table 4. Explaining Contribution Dynamics with and without Compensation

\begin{tabular}{|l|c|c|}
\hline & $\begin{array}{c}\text { Model 1 } \\
\text { Data from baseline and compen- } \\
\text { satory treatments pooled }\end{array}$ & $\begin{array}{c}\text { Model 2 } \\
\text { Compensatory treatment } \\
\text { data only }\end{array}$ \\
\hline & $\begin{array}{c}\text { Dependent variable=difference between contribution in } \\
\text { current period and prior period }\end{array}$ \\
\hline Compensation dummy & $6.916^{* *}$ & $0.299^{* * *}$ \\
\hline Lagged profit & $0.525^{* * *}$ & \\
\hline Compensation dummy*lagged profit & $-0.221^{* *}$ & $0.406^{* * *}$ \\
\hline Period & $0.469^{* * *}$ & $-0.015^{* * *}$ \\
\hline Lagged total profit & $-0.013^{* * *}$ & $1.045^{* * *}$ \\
\hline Compensation dummy*lagged total profit & $-0.0037^{* * *}$ & $-0.068^{*}$ \\
\hline Lagged received sanction & & $-8.618^{* * *}$ \\
\hline Ave. contrib., $1^{\text {st }}$ period & $-0.034^{+}$ & 1392 \\
\hline Constant & $-15.401^{* * *}$ & $<0.001$ \\
\hline $\mathrm{N}$ & 1972 & 0.1615 \\
\hline $\mathrm{p}$ model & $<0.001$ & 0.0290 \\
\hline $\mathrm{R}^{2}$ within & 0.1035 & 0.1522 \\
\hline $\mathrm{R}^{2}$ between & 0.1411 & \\
\hline $\mathrm{R}^{2}$ overall & 0.0965 & \\
\hline
\end{tabular}

Note. Random effects models. *** $\mathrm{p}<.001, * * \mathrm{p}<.01, * \mathrm{p}<.05,{ }^{+} \mathrm{p}<.1$

Overall the compensatory treatment somewhat improves the public good compared to the baseline but the effect is not strong enough to avoid the common deterioration in cooperation over time. This can be interpreted as a limitation on damages regimes, such as our compensatory treatment, that systematically preclude relative non-contributors from having to pay the full cost to the public good of their non-optimal contribution. Can other damages rules improve the outlook?

\subsection{Class Action Damages Treatment}

Our second treatment explores a difference between traditional compensatory damages in bipolar litigation and possible damages in aggregate litigation, such as class actions. In each period, as before, only the active player is entitled to receive damages. This active member is, however, no longer constrained to claiming only the personal damage caused her by the low contributors. In the spirit of aggregate litigation, the low contributors' behavior now exposes them to greater damages, those suffered by the four person group rather than those suffered by an individual.

In this treatment, low contributors are less able to externalize the costs they impose on the group. They may have to pay up to the full amount of harm done and, in any event, can usually be required to pay more than if damages were limited to harm to a single victim. In this treatment, therefore, from low contributors' perspectives, the risk of loss is more like that in aggregate litigation. The active player may however only claim damages from those other group members who have contributed less than her. This limitation parallels the requirement that, even in a class action, showing personal harm is a precondition to recovery. 
Figure 3 shows that the availability of aggregated damages induces a different contribution dynamic over time. Contributions in the aggregate treatment start at a slightly lower level than in the compensatory treatment, but they are almost stable over time and particularly stable in the last 10 periods. In contrast, as shown in Figure 1 and reproduced in Figure 3, the decay in contributions is pronounced if the active player may only claim compensation for her individual damage.

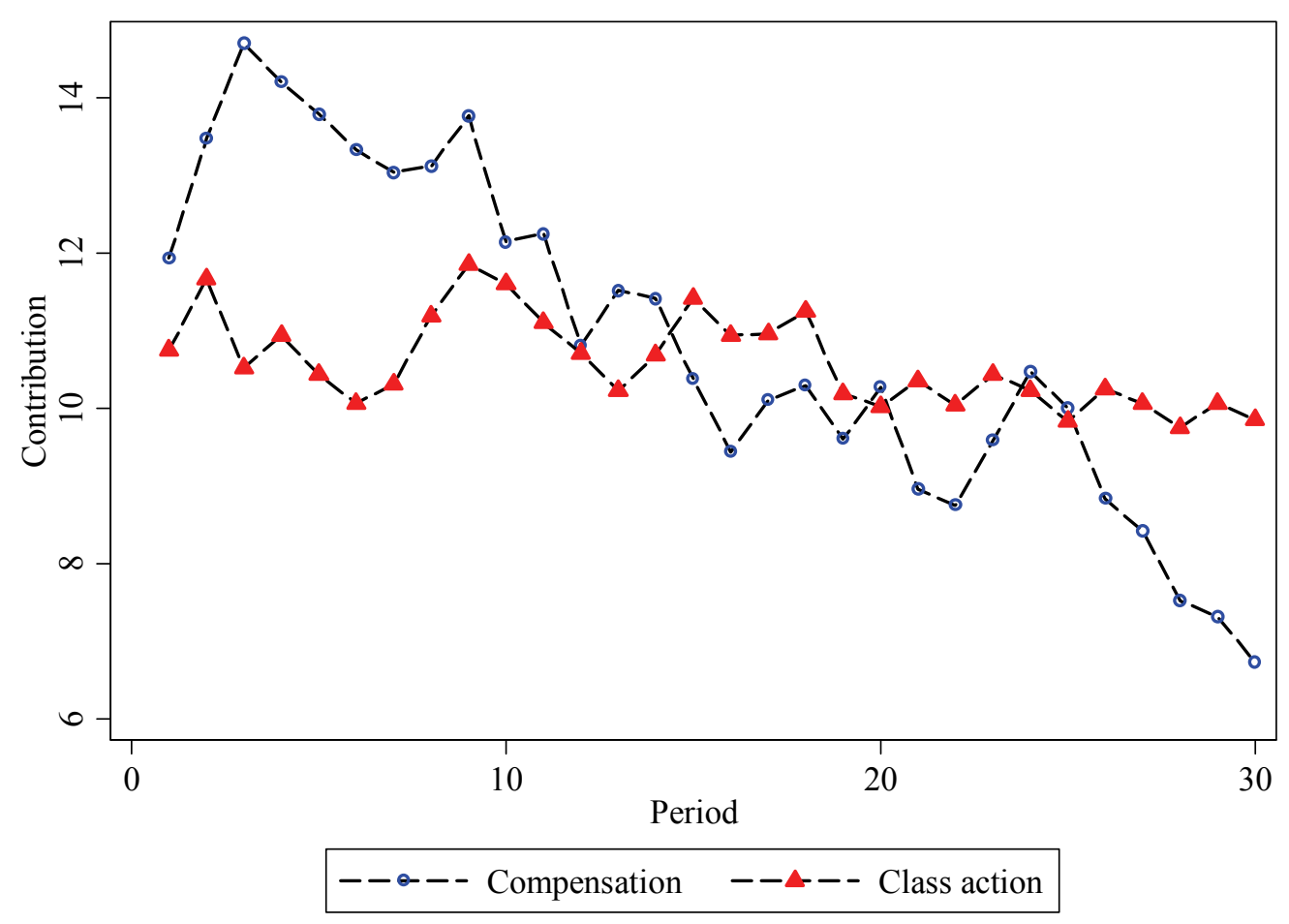

Figure 3. Compensation vs. class action treatments

Tests of the central tendency of the contributions in compensation compared to class action do not yield significant results. Figure 3 suggests why. In early periods in the class action treatment, contributions are significantly below the compensatory treatment. In later periods, contributions in the class action treatment exceed the contributions in the compensatory treatment. The central tendency measures, mean and median of contributions, do not account for the changing dynamic over time. But Figure 3 nevertheless shows a noticeably different pattern for the class action and compensatory treatments. Unlike the pattern for compensatory treatment, the deterioration in cooperation over time flattens out as participants gain experience. Both the slope and intercept of the contribution patterns over time may differ.

To explore this, Table 5 reports regression models in which the dependent variable is a participant's contribution to the public project. As in Table 3, we report both random effects Tobit models and multilevel models. Compensation is a dummy explanatory variable to distinguish between the compensatory treatment and the class action treatment. Average contribution, $1^{\text {st }}$ period, is each group's average contribution in the first period of the experiment, which is used, as in Table 3, to account for group effects in the Tobit models. In the multilevel models, random 
intercepts account for group and individual effects. Period is a variable to track periods 2 to 30 in model 1, periods 1 to 30 in model 2, periods 11 to 30 in models 2 and 5, and periods 21 to 30 in models 3 and 6 .

The interaction term, equal to the product of the compensation dummy variable and period, is significant and negative in all models, suggesting that, compared to the compensatory treatment, the class action treatment leads to slower deterioration in cooperation. The model conforms well to the pattern in Figure 3. The intercept for the compensatory treatment is positive and significant, corresponding to the higher level of contributions in the early periods for the compensatory treatment. The interaction term is negative and highly significant, confirming that contributions in the compensatory treatment decline over time significantly faster than contributions in the class action treatment. The figure suggests that for the last ten periods in the class action treatment there is no noticeable decline in contributions. The period variable is small and insignificant over the last 10 periods. The increased damages available in the class action treatment stem the classic public goods experiment trend of deteriorating cooperation over time. Holding the low-contributors liable for a greater share of the harm they impose leads to improved behavior from the perspective of social welfare. Note that this is not an effect of selfishness. Selfish players contribute nothing throughout the game. Yet those players who are at all sensitive to social disapproval react more safely if they run a risk of more serious sanctions.

Table 5. Difference Between Class Action and Compensation Damages Treatments

\begin{tabular}{|c|c|c|c|c|c|c|}
\hline & $\begin{array}{c}\text { Model } 1 \\
\text { periods } \\
2-30 \\
\end{array}$ & $\begin{array}{c}\text { Model } 2 \\
\text { periods } \\
11-30\end{array}$ & $\begin{array}{c}\text { Model } 3 \\
\text { periods } \\
21-30\end{array}$ & $\begin{array}{c}\text { Model } 4 \\
\text { periods } \\
1-30 \\
\end{array}$ & $\begin{array}{c}\text { Model } 5 \\
\text { periods } \\
11-30 \\
\end{array}$ & $\begin{array}{c}\text { Model } 6 \\
\text { periods } \\
21-30 \\
\end{array}$ \\
\hline & \multicolumn{3}{|c|}{ Tobit models } & \multicolumn{3}{|c|}{ Multilevel models } \\
\hline & \multicolumn{6}{|c|}{ Dependent variable=amount contributed to the public good } \\
\hline Compensation dummy & $5.931 * * *$ & $4.665^{*}$ & $9.565^{*}$ & $3.240 *$ & 2.266 & 4.740 \\
\hline Ave. contrib., $1^{\text {st }}$ period & -0.269 & -0.102 & 0.373 & & & \\
\hline Period & -0.035 & -0.072 & -0.124 & $-0.039 *$ & $-0.062 *$ & -0.048 \\
\hline Compensation * period & $-0.364 * * *$ & $-0.307 * * *$ & $-0.508 * * *$ & $-0.191 * * *$ & $-0.149 * * *$ & $-0.242 *$ \\
\hline Constant & $8.913 * *$ & $14.182 * * *$ & $18.768 * * *$ & $11.193 * * *$ & $11.684 * * *$ & $11.305 * * *$ \\
\hline Number of observations & 2784 & 1920 & 960 & 2880 & 1920 & 960 \\
\hline Number of periods & 29 & 20 & 10 & 30 & 20 & 10 \\
\hline Number of individuals & 96 & 96 & 96 & 96 & 96 & 96 \\
\hline Number of groups & 24 & 24 & 24 & 24 & 24 & 24 \\
\hline left censored & 448 & 400 & 243 & & & \\
\hline right censored & 638 & 432 & 210 & & & \\
\hline$\sigma$ (individual) & & & & $2.585 * * *$ & $2.274 * * *$ & $2.000 * * *$ \\
\hline$\sigma$ (group) & & & & $3.589 * * *$ & $4.691 * * *$ & $5.290 * * *$ \\
\hline $\mathrm{p}$ model & $<0.001$ & $<0.001$ & $<0.001$ & $<0.001$ & $<0.001$ & $<0.001$ \\
\hline
\end{tabular}

Note. Models (1)-(3) report random effects Tobit models of the amount contributed to the public good by each participant in each period, with censoring at 0 and 20 ECUs. Models (4)-(6) are multilevel models that include random intercepts for group and individual. Random effects interval regression models yield results similar to those in models (4) and (5). Model (6) failed to converge. The models include data only from the compensation and aggregate treatments. $* * * \mathrm{p}<.001, * * \mathrm{p}<.01, * \mathrm{p}<.05$. 
One concern raised by Figure 3 is that the significant interaction term may be a consequence of the higher early period contributions in the compensatory treatment, as shown in periods 1 to 10 in Figure 3. The models in Table 5 limiting the sample to the last 20 and last 10 time periods show that the interaction term persists over time to be negative and statistically significant. The improvement in social welfare over time is not an artefact of high early-period contributions in the compensatory treatment. We now reject Prediction 2: there is a pronounced difference between a rule that only allows the plaintiff to claim her own damage, and a rule allowing overall damage to be redressed. We do not simply find a vigilance effect. By contrast, we have further provisional support of Prediction 3: in comparison between these two treatments, there is a positive effect of more severe sanctions on the time trend, but not on the level of contributions.

To explain the class action treatment's effect, we again analyze the factors that are associated with a change in contributions over time. We again seek to explain this change as a function of a dummy variable for whether the participant was required to pay damages in the prior period, the participant's profit in the prior period, and the participant's accumulated profit in all prior periods.

In the class action treatment, contributions increased by an average of 2.9 ECUs when the participant had been required to pay damages in the prior period $(\mathrm{N}=253)$ and decreased by an average of 0.9 ECUs when the participant did not pay damages $(\mathrm{N}=791)$. The nonpayment figure excludes the active player in the prior period because the active player in a period cannot be punished. The difference is highly statistically significant $(\mathrm{p}<0.001)$ using a t-test, a Mann-Whitney test, or a multilevel model that accounts for the nonindependence of observations across individuals and groups. The strong association between prior period punishment and increased contributions persists even in the last 10 periods, when overall contributions are level. In the last ten periods, contributions increased by an average of 2.7 ECUs when the participant had been required to pay damages in the prior period $(\mathrm{N}=81)$ and decreased by an average of 0.9 ECUs when the participant did not pay damages $(\mathrm{N}=279)$. The difference is highly statistically significant $(\mathrm{p}<0.001)$ using a t-test, a Mann-Whitney test, or a multilevel model.

Figure 4 shows the relation between the change in contributions and prior period profit for the class action treatment (4A and 4B). Each subfigure displays a scatterplot and the kernel smoothed line that best fits the data. There is no association between accumulated profit and change in contribution. The association between prior period profit and change in contribution is substantial and positive only for prior period profits of less than about 22 ECUs. 


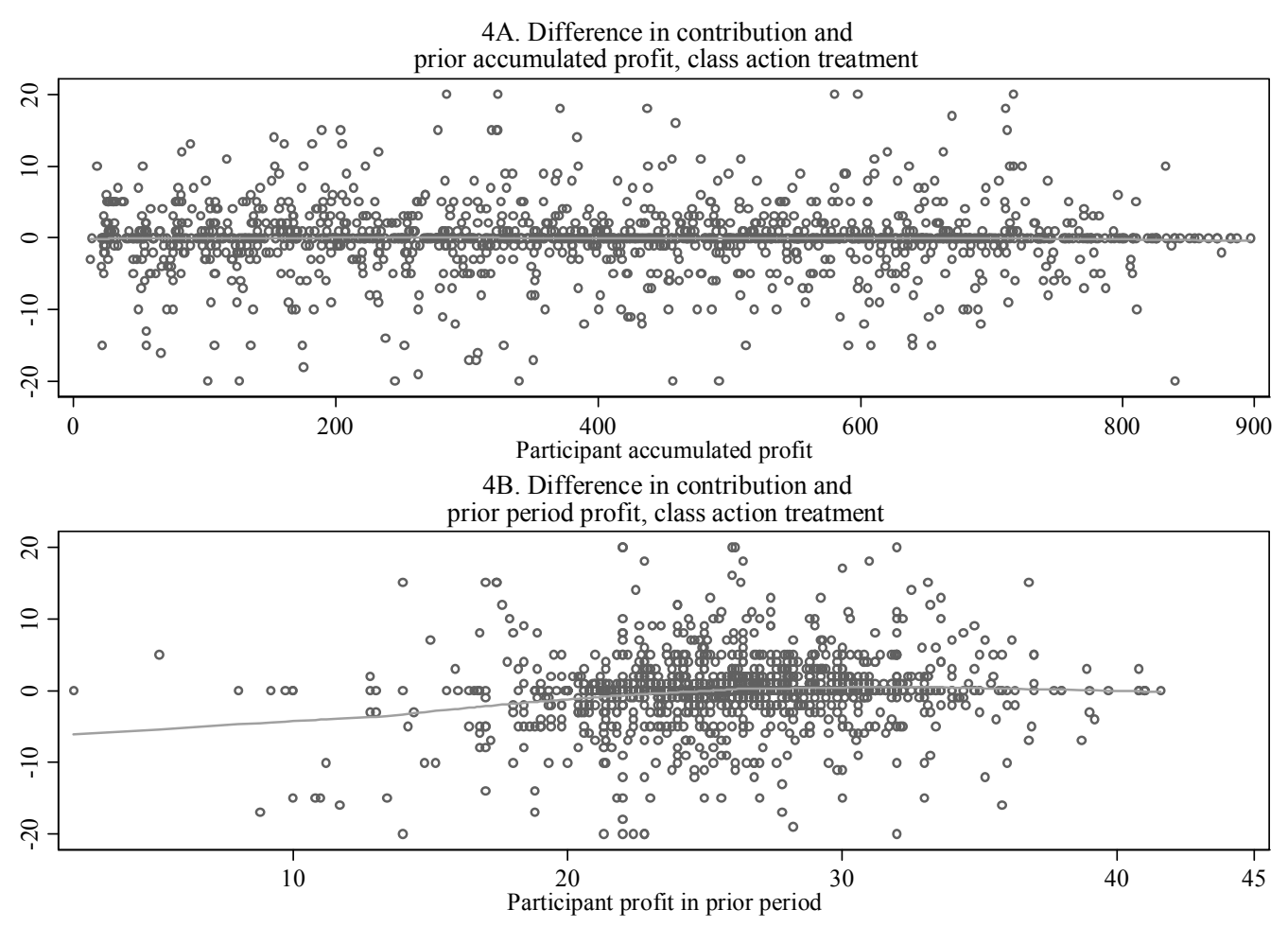

Figure 4. Change in contribution and prior profit, class action treatment

The class action treatment produces relatively stable contributions over time. It does so while reflecting the reaction of participants to suffering prior period damages. They increase their contributions in reacting to prior damages even when contributions have stabilized in the last 10 periods. Regression models of the change in contribution for the compensatory treatment are reported in Table 7 below.

\subsection{Punitive Damages Treatment: Damages Limited by Player Income}

Our third treatment limited damages to the punished player's income received in the period without a limit based on the harm the player caused to the active player or to the four person group. This treatment is analogous to damages rules that allow a claimant to seek damages beyond that necessary to compensate the claimant, and that can even transcend the harm suffered by the class of victims to which she belongs. As noted above, the treatment is analogous to punitive damages or to aggravated damages in some countries. We will refer to it as the punitive treatment.

As Figure 5 shows, in this treatment contributions increase over time. While contributions no longer decay if damages to the group can be recovered, they also do not improve over time. Once the allowed damages increase beyond harm caused to the group or the active player, participants learn to behave well. One question the figure raises is the large decline in contributions from period 20 to period 21. This 2.1 drop in average ECU contribution is by far the largest for any treatment or period in the data (see, for example, Figures 1 and 3). We explored characteristics of period 20 and found no unusual pattern with respect to the rate or size of punishment, or 
the size of contributions. ${ }^{9}$ It appears to be random fluctuation that reset the contribution levels, which tend to be serially correlated, which then again increased over time after this random shock.

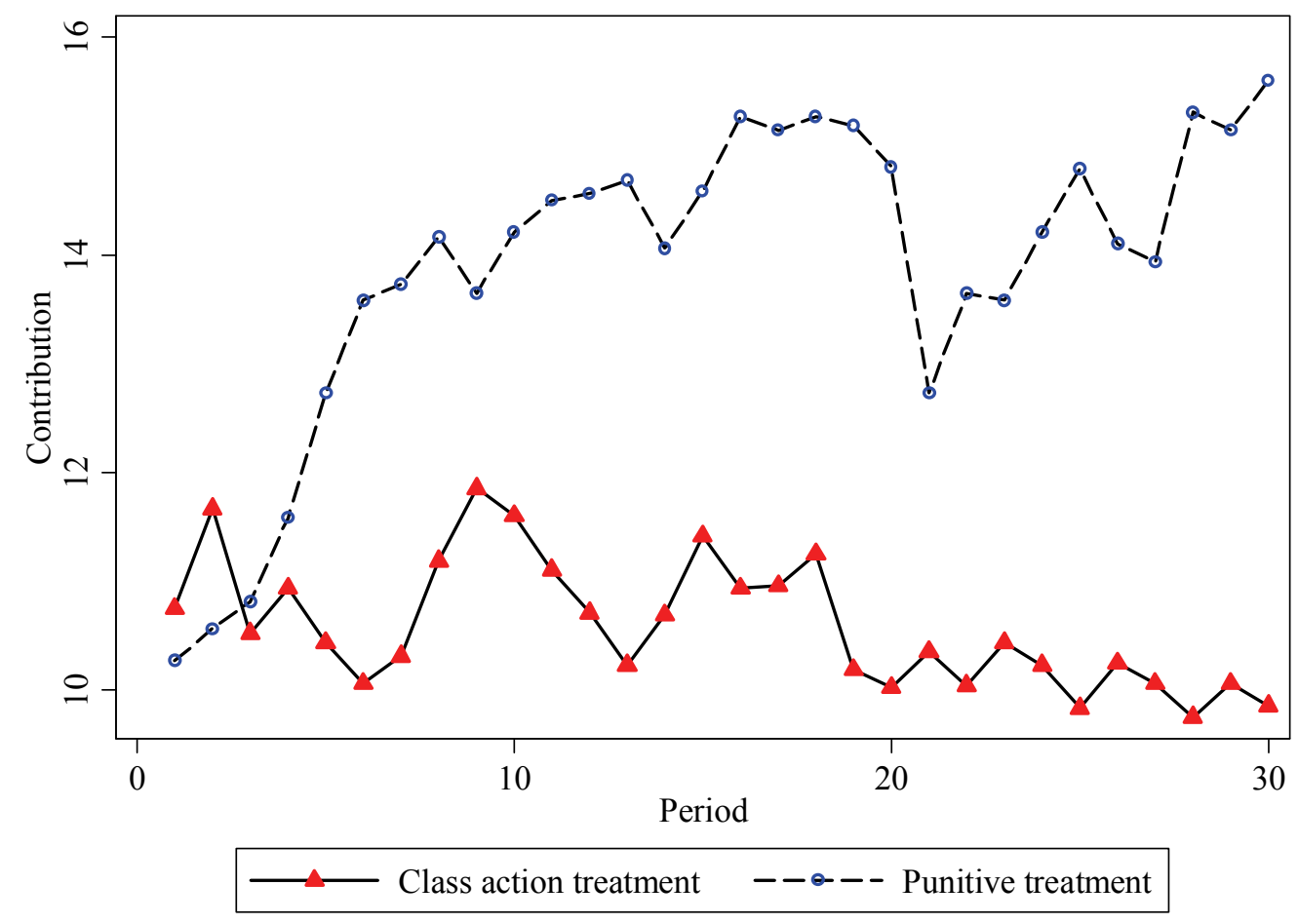

Figure 5. Effect of damage limit on contributions

Non-parametric tests yield a significant difference in the level of contributions between the class action and the punitive treatments (Mann Whitney, $\mathrm{N}=24, \mathrm{p}=.0496$ ), and a weakly significant difference between the compensatory and the punitive treatments (Mann Whitney, $\mathrm{N}=24, \mathrm{p}=$ .0833). The modest significance level between these treatments is again attributable to measures of central tendency not accounting for the crossing of the trends over time. Mean first differences are significantly different at conventional levels in both comparisons (compensation vs. punitive, Mann Whitney, $\mathrm{N}=24, \mathrm{p}=.0005$; class action vs. punitive, $\mathrm{N}=24, \mathrm{p}=.0379$ ). Regression models similar to those in Tables 3 and 5 confirm a highly statistically significant difference in the slope of contributions over time between the class action and punitive treatments. This is further evidence against Prediction 2. The difference between the baseline and all treatments may not be attributed to a mere vigilance effect. The more severe sanctions are allowed to be, the more participants align their behavior with the socially efficient outcome. The severity of the threat is also responsible for the development of contributions over time. If maximum sanctions are light, the downward trend may not be stopped. If sanctions are allowed to match overall harm, there is no time trend. If sanctions are draconian, contributions over time come very close to the social optimum. This provides support for Prediction 3. Note again that this is not a self-

9 The decline is not attributable to a single group. And no similar jump appears in the forfeiture punitive treatment, shown in Figure 11 below. 
ishness effect. Even in the punitive treatment, selfish players make zero contributions throughout. Finally, and remarkably, despite the fact that the sanctioning power, and frequently also actual sanctions, are patently unfair, the large majority of participants nonetheless adjusts their contributions upwards. We see no reactance effect, and reject Prediction 4.

Since we have already established treatment effects non-parametrically, we graphically report only marginal effects of the difference between the class action and the punitive treatments over time, from a random effects Tobit regression that controls for the time trend and its square (the square term accounts for the flattening of the increase in contributions in the punitive treatment over time), both interacted with treatment, and for the mean contribution in the respective group in the first period. Figure 6 shows a significant treatment effect for all but the second period. The treatment difference grows over time until period 25.

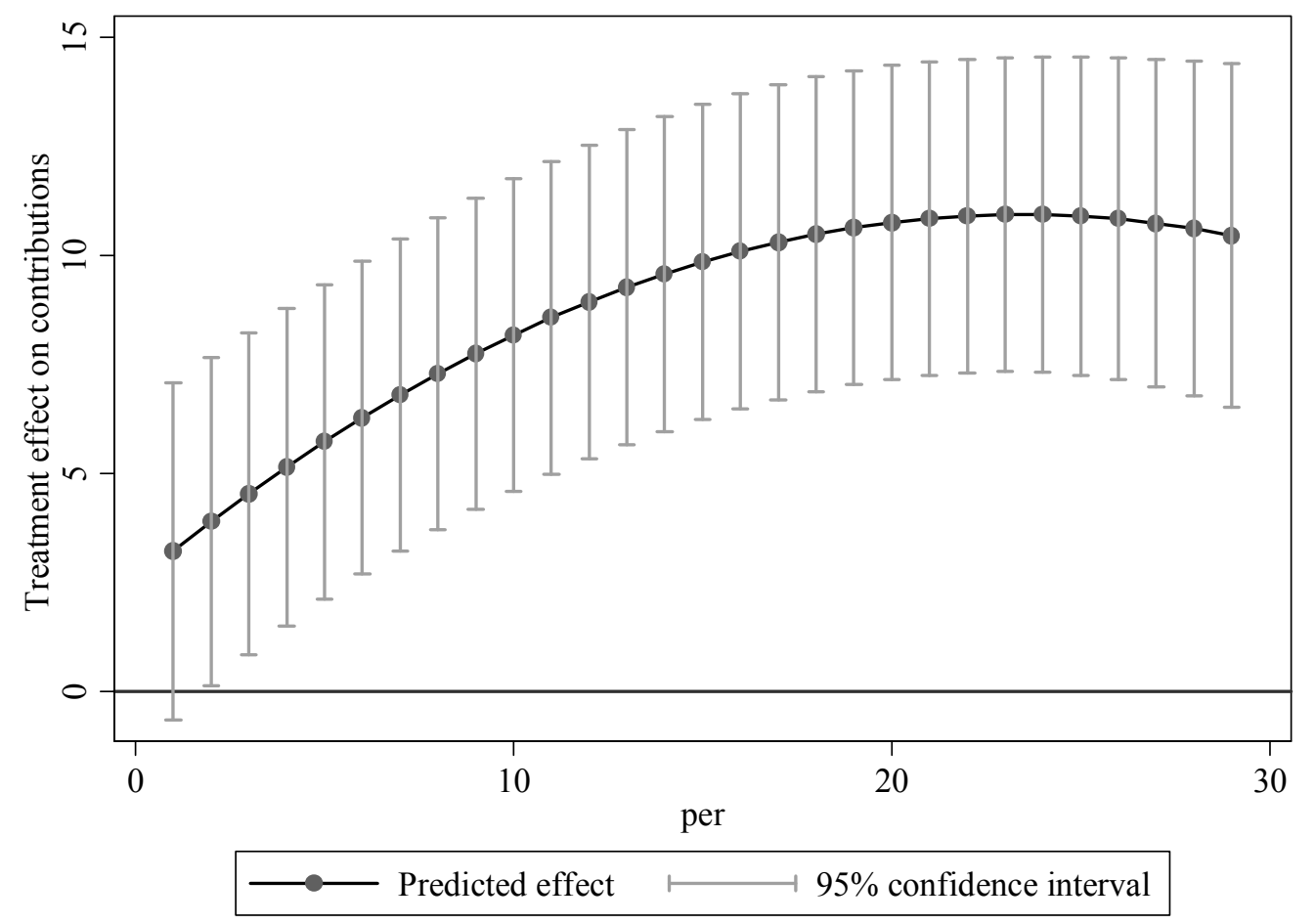

Figure 6. Marginal effects of the difference between class action and punitive treatments over time

Note. The figure is based on a random effects Tobit model, controlling for period*punitive treatment dummy variable, period ${ }^{2 *}$ punitive treatment dummy variable, and group level average contributions in the first period. Data are from the class action and punitive treatments only, and from periods 2-30 only. $\mathrm{N}=2784$, p model $<0.001$.

To explain the punitive treatment's positive effect, we compare its contribution dynamics with that of the class action treatment over time. Punitive treatment contributions remain responsive to prior period damages activity but are less strongly associated with it than in the compensatory treatment. For nonactive participants in the prior period, the correlation coefficient between the change in contributions and the amount of prior period damages is $0.165(p<0.0001)$ in the punitive treatment compared to $0.355(\mathrm{p}<0.0001)$ in the class action treatment. For nonactive partic- 
ipants, contributions increased by an average of 0.2 ECUs when the participant had been required to pay damages in the prior period $(\mathrm{N}=928)$ and decreased by 0.5 ECUs when the participant did not pay damages in the prior period $(\mathrm{N}=116)$, but that difference is not statistically significant using a t-test, a Mann-Whitney test, or a multilevel model that accounts for the nonindependence of observations across individuals and groups. Nor is it significant in subgroups of time periods.

Exploring the patterns of contributions and damages provides some understanding of the diminished role of prior period damages on contribution changes. Table 6 describes features of contributions and damages for the treatments. The difference in contributions between the current period and prior period, shown in the first row, is positive for the punitive treatment and small and negative for the class action treatment, and is consistent with Figure 5's overview of the contribution patterns. The table's second and third rows show the relative absence of change from the prior period dominates in the punitive treatment, with two-thirds of the observations having no change and over 50 percent contributing the maximum 20 ECUs. These figures are much lower for the class action treatment. This absence of change makes it difficult to model the sources of increased contribution over time in the punitive treatment. This difficulty is further compounded by a key potential explanatory variable being almost invariant in the punitive treatment. The fourth row shows that damages were imposed on almost 90 percent of the participants in the $p u$ nitive treatment compared to only about 25 percent in the class action treatment. So this variable is unlikely to be very helpful in explaining punitive treatment contribution dynamics. The last two rows show that, in the punitive treatment, sanctions much more severe are also much more frequent.

Table 6. Characteristics of Class Action and Punitive Treatments

\begin{tabular}{|l|c|c|}
\hline & Class action treatment & Punitive treatment \\
\hline Mean change in contribution from prior period & -0.03 & 0.18 \\
\hline No change in contribution from prior period & $39 \%$ & $66 \%$ \\
\hline Percent making maximum contribution (20 ECUs) & $16.5 \%$ & $53.5 \%$ \\
\hline Damages imposed in prior period* & $24 \%$ & $89 \%$ \\
\hline Mean damages amount in ECUs in prior period* & 0.97 & 22.45 \\
\hline Median damages amount in ECUs in prior period* & 0 & 24.0 \\
\hline Mean damages as \% of contribution in prior period* & $17.1 \%$ & $223.2 \%$ \\
\hline Mean profit in prior period* & 25.3 & 5.7 \\
\hline
\end{tabular}

Note. Damages and profit rows, indicated by a *, exclude active player in prior period.

Table 7 reports regression models of the change in contributions as the dependent variable. Explanatory variables are the lagged period profit, the lagged punishment amount, period, and average group contributions in the first period. Models (3) and (4) exclude the active players in the prior period because their immunity from damages could make them less responsive to prior pe- 
riod activity. ${ }^{10}$ Multilevel models that drop the average first period contribution variable and include the first period results do not noticeably differ from the Table 7 models. ${ }^{11}$

Table 7. Regressions Explaining Contribution Dynamics: Class Action vs. Punitive Treatments

\begin{tabular}{|l|c|c|c|c|}
\hline & $(1)$ & $(2)$ & $(3)$ & $(4)$ \\
\hline & \multicolumn{2}{|c|}{ Dependent variable=difference between contribution in current } \\
& \multicolumn{4}{|c|}{$\begin{array}{c}\text { period and prior period } \\
\text { perion }\end{array}$} \\
\hline & Class action & Punitive & Class action & Punitive \\
\hline Lagged profit & $0.195 * * *$ & $0.0312^{* * *}$ & $0.283^{* * *}$ & $0.318^{* * *}$ \\
\hline Lagged sanction amount & $0.740^{* * *}$ & $0.111^{* * *}$ & $0.753^{* * *}$ & $0.313^{* * *}$ \\
\hline Period & 0.00891 & $-0.0481 * * *$ & 0.00753 & $-0.0399^{* *}$ \\
\hline Ave. contrib. 1st period & -0.0135 & -0.00939 & -0.0120 & $-0.162^{* * *}$ \\
\hline Constant & $-5.714^{* * *}$ & $-1.697 * * *$ & $-7.875^{* * *}$ & $-6.514 * * *$ \\
\hline Observations & 1392 & 1392 & 1044 & 1044 \\
\hline Number of individuals & 48 & 48 & 48 & 48 \\
\hline Number of groups & 12 & 12 & 12 & 12 \\
\hline
\end{tabular}

Note. The table reports random effects models with random effects for groups. $* * * p<.001,{ }^{* *} \mathrm{p}<.01,{ }^{*}$ $\mathrm{p}<.05$.

In both treatments, those who were obliged to pay higher damages in the previous period responded to the sanction by increasing their contributions more. The size of the coefficient is smaller in the punitive treatment, which is consistent with less variation in contributions and damages in that treatment, as shown in Table 6. Participants in both treatments also contributed more as prior period profits increased, an effect that is somewhat larger in the punitive treatment than in the class action treatment. In summary, we have a fairly simple story: the much higher severity of sanctions in the punitive treatment increases contributions. Tables 4 and 7 show that participant contributions in a period respond to damages assessments in the prior period.

One concern about this finding is the punitive treatment's allowance of opportunism by the active player. The player can take all period income, for her own benefit, from other participants regardless of the level of the punished player's contributions. To assess the presence and degree of such opportunism, consider a characteristic set of contributions and profits (period income) of a dozen distinct participating individuals from the punitive treatment, as shown in Figure 7 . Period income heavily fluctuates. Some participants make a large profit in some periods. Others make zero profit in other periods. Some participants are prepared to abuse their sanctioning power once they are selected as the active player. Nonetheless, the figure also shows that many par-

10 Our design involves an element of luck. Each period, one participant is randomly singled out to have the active role. This element of the design resonates with popular perception of punitive damages. In the press, having a claim for punitive damages against a wealthy defendant is frequently equated with landing the jackpot. But lagged active player status is highly correlated with lagged profit. So we cannot include both variables in a single model.

11 The change in contribution can be a function of the size of the lagged contribution and Table 2 shows substantially different contributions between the class action and punitive treatments. This counsels in favor of using the percent change as the dependent variable. But that amount is undefined for prior period contributions of zero. And the Appendix shows at least 100 zero contributions in each treatment. As an alternative way to account for varying contribution size, we have run models that include the lagged contribution as an explanatory variable, where a zero value can be included. Results did not noticeably differ though such models suffer from having the lagged contribution on both sides of the equation. 
ticipants contribute their entire endowments, either throughout the game, or after a certain period of learning. If we focus solely on the participants selected to be active in the prior round of punitive treatment, a majority contributed their full endowment in the next period of contributions. The punitive treatment's opportunity of high personal profit did not systematically discourage those able to profit from contributing to the public good.

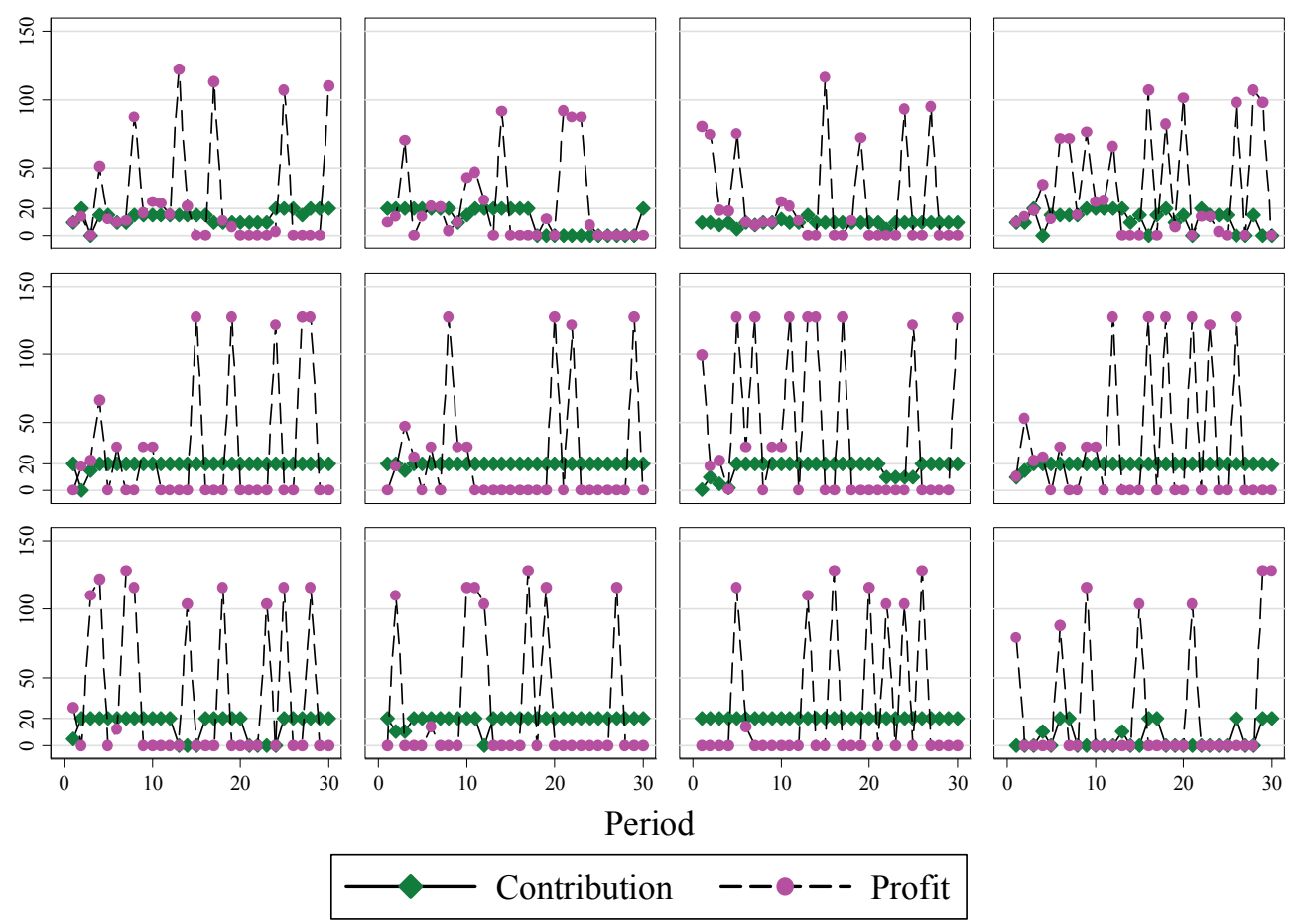

Figure 7. Exemplary individual data from the punitive treatment

Note. The figure shows the contributions and period income for 12 individuals in the punitive treatment.

The opportunism concern is sometimes explored by evaluating what is called "antisocial punishment," in which a lower contributing participant punishes a higher contributing participant (for example Cinyabuguma, Page et al. 2006; Herrmann, Thöni et al. 2008). This behavior is possible only in our punitive treatment. To assess its influence on contributions, we divide the punitive treatment sample into observations in which the active player contributed more than the punished player and those in which they did not. Antisocial punishment was common in this treatment with active players punishing in 676 of 777 ( 87 percent) instances in which the active player contributed less than the punished player. But punishment occurred at a higher rate 286 out of 393 (94.4 percent) when the active player contributed more. Figure 8 shows the two groups' pattern of contributions over time. 


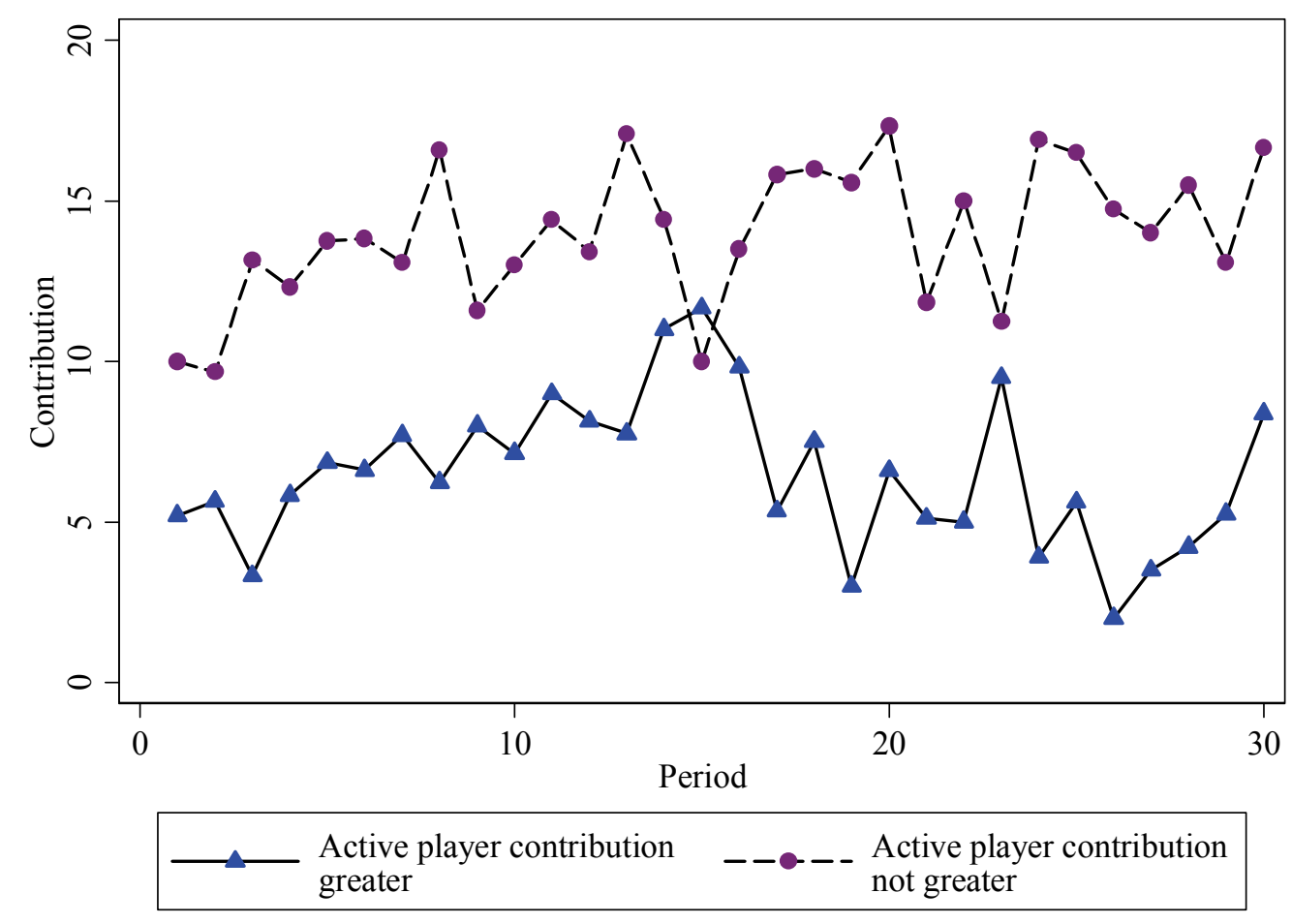

Figure 8. Punitive treatment contributions, shown separately based on active player's contribution level

The figure suggests ambiguity in our punitive treatment's results. If one is concerned about antisocial punishment, then the figure's lower line better captures the social welfare benefit of the punitive treatment. That trend line includes only groups in which the active player's contribution exceeded that of all other players. The line suggests at most non-deterioration in cooperation over time but no clear increase in cooperation over time. Further exploration of a similar treatment under conditions limiting the active player's punishment opportunity is warranted.

We shift the focus to the active player's behavior by studying the association between the active player's damages claims in a period and the other players' contributions in that period. Figure 9 shows the damages active players extracted from non-active players as a function of the nonactive players' contributions. It shows that damages declined with increasing contributions, which is consistent with the earlier results showing that non-active participants responded to being punished by increasing contributions. Regression models confirm that this is a highly statistically significant result. This relationship of course not holds in each and every case. As Figure 7 shows, some active players are just greedy and take whatever the other group members have earned, and ignore how much they have already contributed to everybody's profit by investing a large share of their endowment. Yet as the regression demonstrates a passive player still stands the highest chance to keep some or even all of her first stage profit if she had made a substantial contribution to the joint project. 

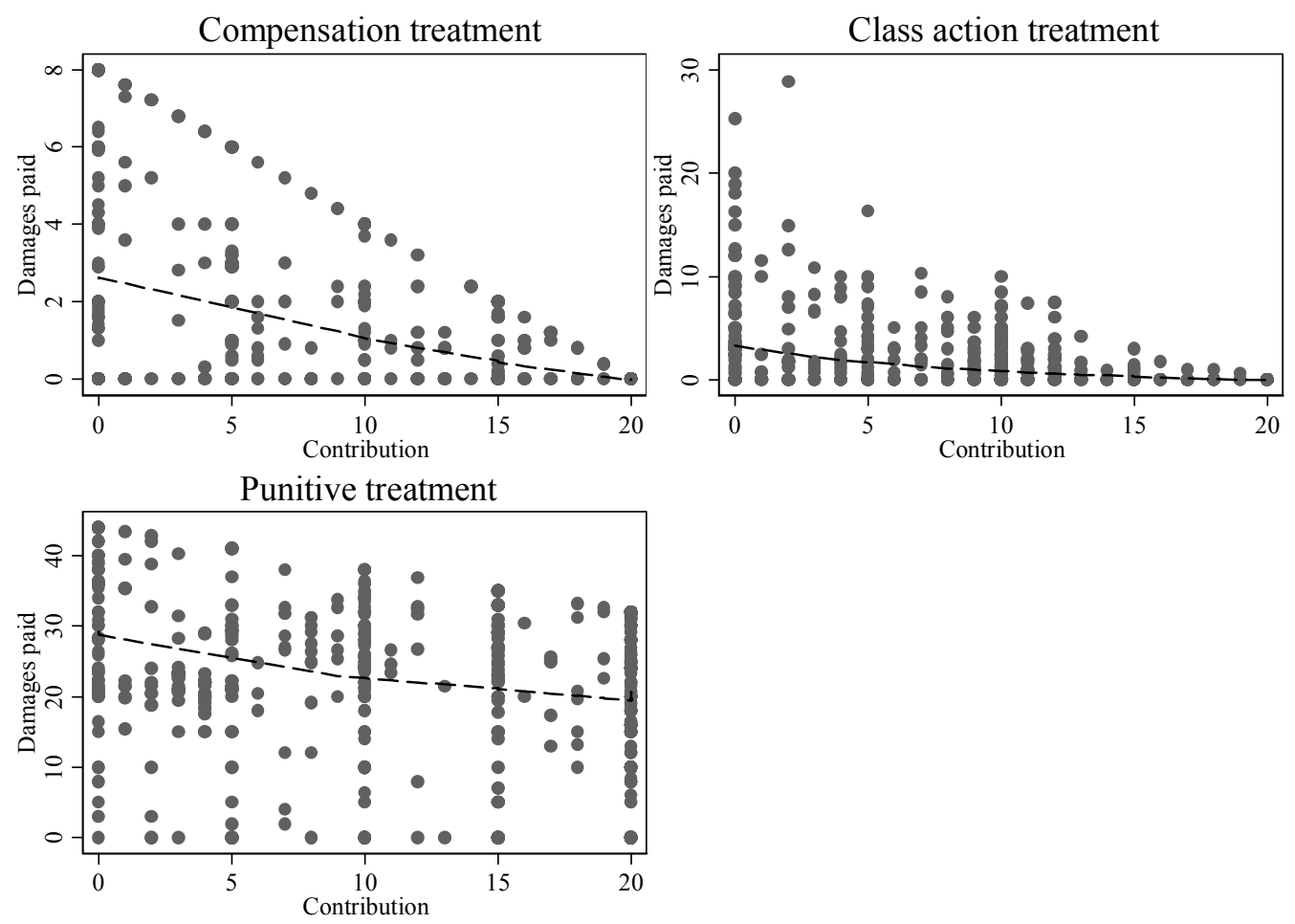

Figure 9. Relation between damages and contributions, by treatment

Note. The figure shows scatterplots and lowess lines that best fit the relation between damages and contributions for the three treatments.

\subsection{Signaling Intentions: The Forfeit Damages Treatments}

From the perspective of a participant solely motivated to maximize her profit, it does not matter whether a criminal court imposes a fine or whether a victim sues for damages. All such a participant is interested in is two parameters: what is the probability of losing money, and how much money does she stand to lose? For such an actor, fines and damages are perfect substitutes. From a behavioural perspective, this might well be different. On the one hand, if a culprit pays a fine, the money does not benefit the victim. The victim at best benefits in psychological terms in that her sense of justice is assuaged. She at most gains utility in terms of retribution and revenge. By contrast, to the extent that the harm itself is pecuniary, if the culprit is obliged to pay damages to the victim, the harm itself is redressed. This might convey additional legitimacy to compensation, which might translate into a stronger beneficial effect on cooperation.

In addition, whenever damages exceed the harm, as they may in our punitive treatment, deterrence comes at the psychological cost of a windfall profit for the claimant. While stronger deterrence is, as we have shown, instrumental, it arguably suffers from generating distributional imbalance. In the punitive treatment, the vast majority of the ECUs wind up in the active player's possession. Participants required to pay damages above harm caused might perceive the excess damages as a selfish act of the group member who is lucky to have the active role, and not as a legitimate technology for restoring incentives. 
To test the presence of these psychological effects on deterrence and cooperation, we repeated all three treatments, but now gave the active group member a second option. Instead of claiming money for herself, she had the option to simply forfeit some or all of the period income of the passive group members. The forfeiture power was subject to the same limits as the power to retain damages amounts. Hence the compensatory/forfeit treatment exactly mirrors the compensatory treatment. If the active player chooses the forfeit option, she can cause to be forfeited at most the difference between her actual profit and the profit she would have had had all other group members contributed at least as much as she did. Likewise the class action/forfeit treatment mirrors the class action treatment. If the active member chooses the forfeit option, she can cause to be forfeited at most as much money as all other group members would have had, had they contributed the same amount as the active player to the joint project. Finally the punitive/forfeit treatment mirrors the punitive treatment. The only limit on the forfeited amount is the period income of the respective passive group members.

Active players rarely use the forfeit damages option, which is not surprising since it gives them no tangible benefit. It was used in about one percent of the available opportunities in the compensatory/forfeit treatment, in about seven percent of the opportunities in the class action/forfeit treatment, and in about three percent of the opportunities in the punitive/forfeit treatment, a total of 56 times. Figure 10 shows the distribution of forfeited amounts, by treatment.
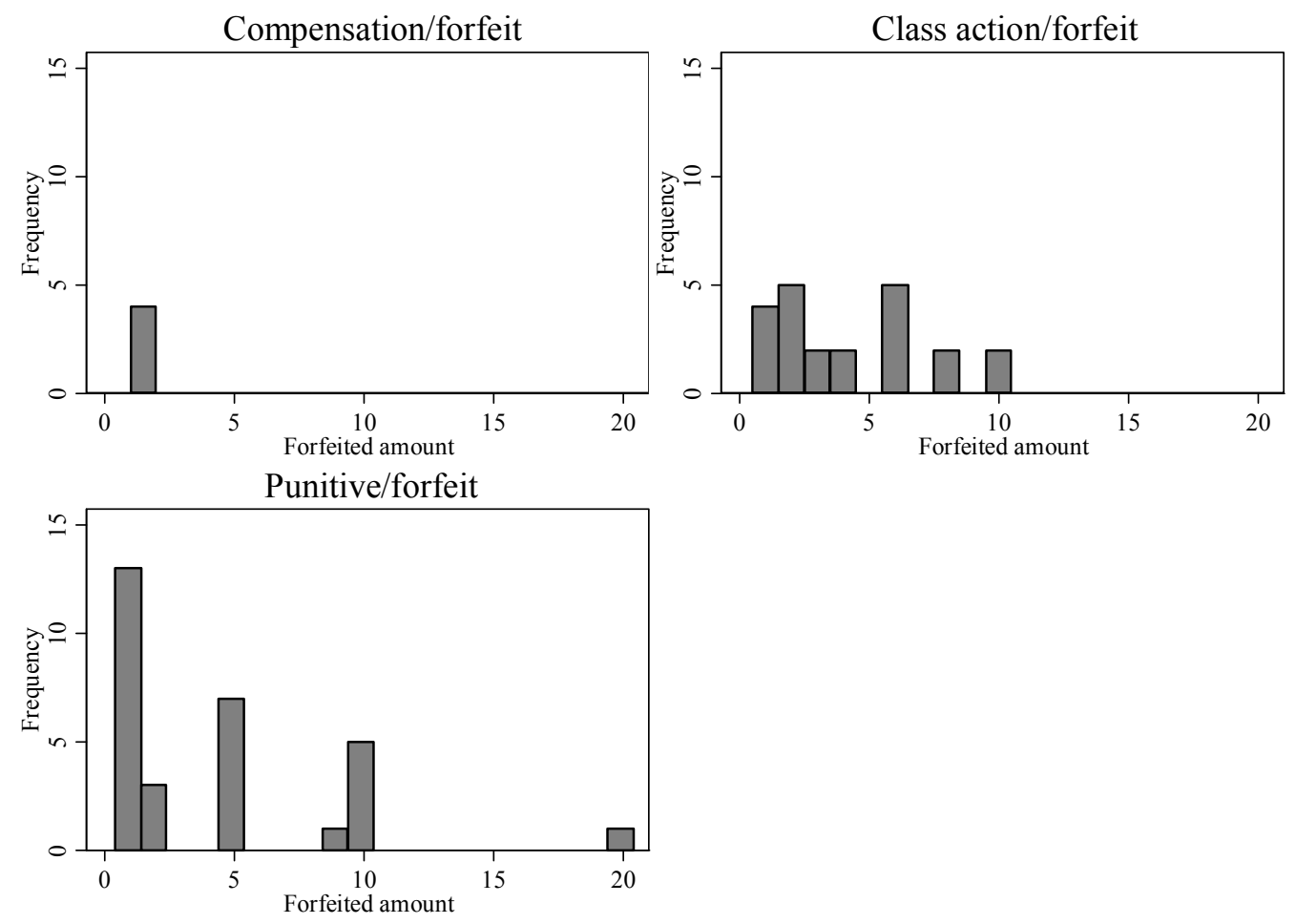

Figure 10. Use of forfeit option, by treatment

Note. Inclusion of observations in the figure is conditional on the presence of a positive forfeited amount. 
Although the forfeit option was rarely used, its availability yields important information. For the passive players in each period, the fact that the active player has the forfeit option changes the interpretation of her claiming damages. If passive members care about intentions, the level of contributions and contribution dynamics might change. Figure 11 shows that the effect of this additional option on contributions is not substantial, whatever the limit for extracting damages from the non-active players. Nonparametric tests over means never yield a significant effect of the forfeit treatments compared to their analogous treatments. Parametrically, with some specifications we find a significant treatment effect. But the marginal effect of adding the forfeit option is never significant.
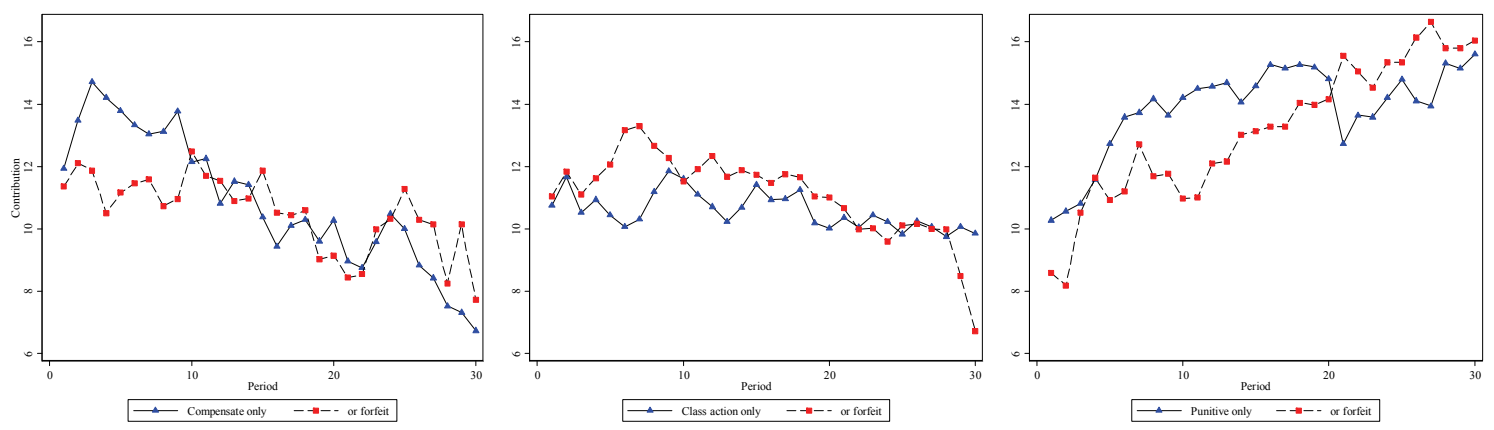

Figure11. Effect of the forfeit option

This is a remarkable finding. Damages work in promoting contributions because they deter antisocial behaviour. We do not find that they work better if it is made salient that the harm imposed on the victim is redressed. And they do not work worse if it is made salient that the claimant gains a windfall profit. Active players not only forsake the possibility to remove any suspicion of selfishness and to signal benevolent motives. Non-active players also do not react negatively to the fact that the additional forfeit option would have given active players this opportunity, but that they have not seized it. In the compensatory, class action, and punitive treatments, we found no significant interactions between the forces driving contribution changes and the forfeit option. For this purpose, we evaluated the same forces, lagged profit, lagged punishment amount, period, average first period earnings, as used to evaluate contribution changes in Table 7.

Eventually, we thus fully support Prediction 3, and reject all competing predictions, including Prediction 5, which expected intentions to matter. Readers should appreciate that we have not found a simple incentive effect. To reiterate: selfish players disregard all sanctions and contribute nothing throughout. Rather, we have shown that players who are not (completely) selfish nonetheless are sensitive to the severity of the threat with sanctions, while they do not care about the intentions of the sanctioning authority. This fits the observation that typical experimental populations are heterogeneous, with a small fraction of unconditional altruists, a larger fraction of selfish players, and a substantial majority of conditional cooperators (Fischbacher, Gächter et al. 2001; Fischbacher and Gächter 2010). The latter participants are willing to cooperate, despite the fact that they forego the opportunity to exploit others, as long as they have little reason to fear being the sucker themselves. For such participants, sanctions matter to the extent that 
freeriding no longer pays. Note that this is not the forward looking argument of standard economic theory. Rather loyal contributors want to see wrongdoers punished. In this perspective, damages even have an advantage over punishment. Since claiming damages is profitable for the active player, ex ante all players may be reasonably confident that the future active player will exploit the opportunity. The certainty of the inflicting the sanction is not an issue. Our results show that these loyal group members desire higher severity.

\section{Discussion}

\subsection{Consistency with Observational Data and Non-Public Good Experiments}

Our results are consistent both with some available evidence outside the laboratory and with other experimental evidence regarding the benefits of class actions (Eisenberg 2007; Güth, Kliemt et al. 2007),

The failure of the compensatory treatment to prevent deterioration in cooperation may help explain persistent troubling behavior by many actors. For example, evidence exists that hospitals do not bear the full costs of the negligent harms they inflict on patients. A study of hospitals in Utah and Colorado found that hospitals bore only 22 percent of the injury-related costs that they generated (Mello, Studdert et al. 2007). Not coincidentally, the scope and impact of medical malpractice is massive (Baker 2005), ${ }^{12}$ and the problem has not materially diminished over time (Landrigan, Parry et al. 2010). By one measure of patient safety quality, the rate of adverse events declined by only one percent between 2000 and 2005 (Agency for Healthcare Research and Quality 2007).

The dynamic quality of the public good experimental paradigm may help explain its deterrencepromoting result, at sufficient punishment levels, compared to an experimental finding that the threat of tort liability does not deter (Cardi, Penfield et al. 2012). Cardi et al.'s respondents were asked in a cross-sectional survey whether tort liability in several scenarios would deter them and no significant deterrent effect was found. That result is consistent with a single-period outcome of no deterrent effect. But a cross-sectional design cannot subject the respondents to the experience of having to pay for anti-social behavior, and then provide them the opportunity to revise their behavior based on their experience with a liability regime. A public good experiment allows that opportunity. The dynamics over time cannot be replicated in a cross-sectional experiment either. The experimental results are not inconsistent; they merely focus on different stages of experience with rules intended to deter.

12 A 1999 Institute of Medicine report found that medical error caused between 44,000 and 98,000 deaths and over one million injuries each year, with an associated cost of $\$ 17$ to $\$ 29$ billion (Kohn, Corrigan et al. 2000). 


\subsection{Further Thoughts on External Validity}

Our experiment lacks some features of actual litigation. In our experiment, no difference exists between claiming and receiving damages. The active player receives whatever she legitimately claims. Of course, in the field, a victim who sues the defendant is not sure to win. Frequently, the interpretation of the law is unclear. If damages are claimed for negligent behaviour, the normative standard frequently depends on local practice and the outcome depends in part on the judge or jury hearing the case. Moreover, not every person who has a viable claim may choose to sue. For a variety of reasons, a person in principle entitled to sue may not have the opportunity to do so. One well-studied reason is the cost of litigation being prohibitively high.

Our equating of claiming and receiving damages, however, does not seriously affect the external validity of our findings. Our experimental design incorporates uncertainty about outcome into participant decisionmaking. The uncertainty in court is one of the justifications of randomly only allowing one of four group members to claim damages, thereby introducing stochastic uncertainty into the design. A second class of uncertainty analogous to the decision not to sue, behavioural uncertainty, results from the active participant's freedom to exercise or not to exercise the right to collect from other participants.

That both sources of uncertainty are likely to matter is also suggested by earlier experimental findings.If the probability of being punished is small, contributions do not stabilize (Bernasconi, Corazzini et al. 2010) and cooperation decreases. Similarly, if the punishment decisions of participants are only executed with uncertain probability, cooperation declines (Sousa 2010). The same holds if would-be punishers receive an imperfect signal about other participants' contributions (Grechenig, Nicklisch et al. 2010). With respect to the specification of the uncertainty, our design is most closely related to the design by (O'Gorman, Henrich et al. 2009). In that experiment, allowing only one participant per period to punish did not significantly reduce contributions, compared to a design where all were entitled to punish. ${ }^{13}$ This suggests that the treatment differences found in our experiment do not result from punishment being uncertain.

The treatment differences may alternatively result from expectations about the potential loss differing across treatments. This resonates with the finding that contributions increase as the cost to the punisher of inflicting punishment decreases (Egas and Riedl 2008; Nikiforakis and Normann 2008). We contribute to this strand of the literature in that our treatment analogous to punitive

13 Our design is not the same as punishment by the experimenter (Tyran and Feld 2006; Galbiati and Vertova 2008; Bernasconi, Corazzini et al. 2010) because our active participant suffers harm from low contributors and imposes damages. Similarly, it is not the same as punishment by an additional subject who is not one of the group that contributes from endowments to the public good (Engel and Irlenbusch 2010). It is more closely related to experiments in which all participants may punish, but the level of allowed punishment is asymmetric in that different participants can impose different levels of punishment. This turns out to make little difference as asymmetric punishment institutions are as effective in fostering cooperation as symmetric institutions (Nikiforakis, Normann et al. 2010). (Carpenter, Kariv et al. 2010) manipulate the internal architecture of the group and vary whether all group members are monitored rather than varying punishment levels. They distinguish in part between connected networks, in which all group members are monitored by other members, and disconnected networks, in which some participants in a group are not monitored. The connected networks result in significantly higher contributions than the disconnected networks. 
damages implements a draconian sanction with very high potential gains to the active player. It is not obvious that such extreme sanctions also have a socially beneficial effect (which turns out to be the case, though).

Our experiment also provides participants with no explicit behavioural norm. We of course have made this choice to prevent hinting to subjects what constitutes appropriate behavior, an experimenter demand effect. Yet from the design it is clear that all group members contributing their entire endowments is the only choice that simultaneously is efficient and prevents exploiting other participants. Participants know that the randomly selected active participant is not only entitled, but also likely, to claim the maximum permissible amount, which gives them a chance to anticipate which behaviour will trigger which reaction. So participants cannot be certain about who the active player will be or what her behavior will be. But a discernable if not fully certain norm exists and can be acted on.

\section{Conclusion}

We present evidence that a damages rule analogous to the most common measure of damages in contract and tort litigation, the harm to the aggrieved party, is insufficient to deter serious deterioration in cooperation over time. This finding is of particular policy relevance if harm is diffuse, as notably with harm to the environment. A damages rule more closely tied to the full harm noncooperators cause, which is analogous to damages in class action litigation, prevented the pattern of deteriorating cooperation over time. A more Draconian rule of damages, linked to income without requiring harm, promoted increased cooperation over time but at the cost of allowing socially unjust damages. Damages rules can promote socially beneficial behavior, but not all damages regimes will do so and some may do so in an unfair manner.

This experiment has tested only two damages rules reasonably analogous to civil justice compensation practices, the compensatory treatment and the class action treatment. Further information about the social welfare implications of damages rules could be obtained by assessing other damages measures with real-world analogies to determine which ones generate increasing cooperation over time, or at least avoid the common pattern of decaying cooperation. Simple multiples of the damages rules we have explored, analogous to, for example, treble damages rules in U.S. antitrust cases, might be usefully explored. Caps on damages, such as those many states impose in medical malpractice cases and on punitive damages, should also be of interest. And more refined punitive damages treatments could be developed, including some with relations to compensatory harm or to experimentally manipulated simulations of egregious misbehavior. 


\section{Appendix}

\section{Equilibrium Assuming Standard Preferences}

In a public good experiment without sanctions, zero contributions are the best response. If money maximising behaviour is common knowledge, in the unique Nash equilibrium, all contribute zero. Adding costly punishment does not change this prediction. For rational actors do not punish. Therefore nobody expects to be punished. Zero punishment and zero contributions are the only Nash equilibrium.

In the treatments with a forfeit option, using this option is free of charge, but claiming damages rather than using the forfeit option has the additional advantage of increasing the payoff of the active player. If there is a cap, it is the same for both options. Therefore money maximizing agents will not use the option to destroy target income. Compensation is not costly and increases the payoff of the punisher. Therefore money maximizing active players go to the limit, and do so for all other group members.

If damage is limited to harm suffered by the active player herself, in the extreme case she has contributed 20 ECU, while all passive players have contributed 0 . Then she has first stage income 8 . From all others she may take 8 . Her total income is 32 . If she contributes nothing, expecting that all others contribute nothing as well, she has 20 . A player has the active role with $25 \%$ probability. Therefore she compares $1 / 4 * 32+3 / 4 * 8=14<20$. Hence payoff maximising players do not contribute a positive amount in hopes of having the active role. For the eventuality of having the passive role, they anticipate that no other player contributes in hopes of having the active role. Therefore in anticipation no active player has a higher payoff than 20 , which is why the compensation mechanism is never applied. No active player is ever worse off than any passive player. Consequently players do also not have reason to contribute a positive amount to preempt being sanctioned. Hence all players contribute 0 from the beginning.

If damages are only limited by the target's period income, a money maximizing active player takes all period incomes from all other players. This is irrespective of their contributions. With $25 \%$ probability each player may have the active role. In that case she keeps her period income, and takes all passive players' incomes. Therefore each player is best off not contributing at all. Since the sanction is unrelated to the contributions the target player has made, there is also no reason to contribute a positive amount in the interest of preempting being sanctioned.

If the active player may obtain damages based on harm to all players, the maximum loss in the second stage is in the case in which the punisher has contributed 20, while all others have contributed 0 . Then actual group income is $8+3 * 28=92$, while the group would have had 128 , had all contributed 20 . Therefore the damage is $128-92=36$. Since each has only 28 , the maximum compensation that can be taken from either of them is 28 , leaving them with a period income of 0 . This player might instead have contributed 20 . That would have raised group income to $2 * 16$ $+2 * 36=104$. Maximum compensation would be down to 24 . Since this player's period income 
is only 16, she would again put her entire period income at risk. Therefore making a positive contribution in the interest of protecting oneself against compensation claims is not rational. If a player has the active role, she may claim damages. This does not presuppose that she has suffered harm herself. Yet since players who do not expect to have the active role make 0 contributions, the only question is this: does it pay to contribute 20 , in hopes of having the active role? As laid out, this gives a total of 36 in damages, which is more than 20 in the case of 0 contributions. Yet this again has to be weighed with probabilities. $1 / 4 * 36+3 / 4 * 8=15<20$. Therefore also in this treatment no player contributes a positive amount in hopes of having the active role in the second stage. Consequently, no player expects others to make positive contributions, which is why again the compensation mechanism in equilibrium is never applied. 0 contributions by all players is the unique Nash equilibrium in this treatment as well.

None of this changes if we take into account that our game is repeated. In principle, this might matter. Participants might want to invest into building a profitable relationship. Yet we announce 30 periods. In the final period, building a relationship no longer pays. In anticipation, this holds for all previous periods as well, leading to unravelling. 


\section{Distribution of Contributions}
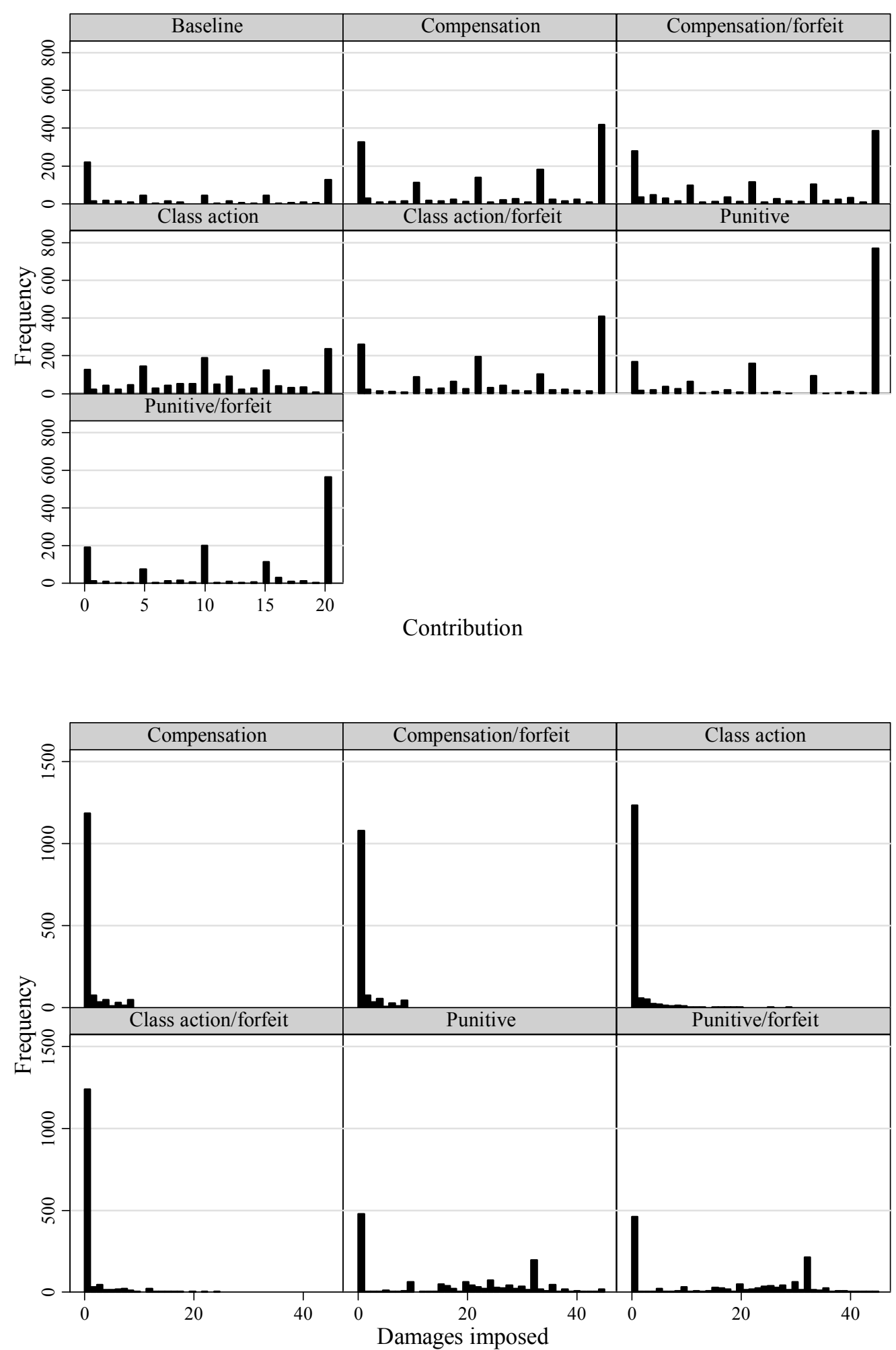

Note. The figures show the distribution of contributions and damages, subdivided by treatment. The "/forfeit" graphs show the retain-or-forfeit treatments. 


\section{References}

Agency for Healthcare Research and Quality (2007). National Health Care Quality Report 2007 http://www.ahrq.gov/qual/nhqr07/nhqr07.pdf.

Baker, Tom (2005). The Medical Malpractice Myth, University of Chicago Press.

Beckenkamp, Martin, Christoph Engel, et al. (2009). Beware of Broken Windows! First Impressions in Public-good Experiments http://ssrn.com/abstract=1432393.

Bernasconi, Michele, Luca Corazzini, et al. (2010). 'Expressive'Obligations in Public Good Games. Crowding-in and Crowding-out Effects

http://www.dse.unive.it/fileadmin/templates/dse/wp/WP_2010/WP_DSE_bernasconi_cora zzini_marenzi_04_10.pdf.

Bracht, JÜrgen, Charles Figuieres, et al. (2008). "Relative Performance of two Simple Incentive Mechanisms in a Public Goods Experiment." Journal of Public Economics 92 (1-2): 54-90.

Brehm, JaCK Williams (1966). A Theory of Psychological Reactance. New York, Academic Press.

Brehm, Sharon S. and Jack Williams Brehm (1981). Psychological Reactance. A Theory of Freedom and Control. New York, Academic Press.

CARdi, W. Jonathan, Randall D. Penfield, et al. (2012). "Does Tort Law Deter Individuals? A Behavioral Science Study." Journal of Empirical Legal Studies 9: ***.

Carpenter, Jeffrey, Shachar Kariv, et al. (2010). Network Architecture and Mutual Monitoring in Public Goods Experiments

http://community.middlebury.edu/ jcarpent/papers/DNM(8).pdf.

Charness, Gary and Matthew Rabin (2002). "Understanding Social Preferences with Simple Tests." Quarterly Journal of Economics 117: 817-869.

Chaudhuri, ANANish (2011). "Sustaining Cooperation in Laboratory Public Goods Experiments. A Selective Survey of the Literature." Experimental Economics 14: 47-83.

Choi, Stephen J. and Theodore Eisenberg (2010). "Punitive Damages in Securities Arbitration: An Empirical Study." J. Legal Stud. 39: 497-547.

Cinyabuguma, Matthias, Talbot Page, et al. (2006). "Can Second-Order Punishment Deter Perverse Punishment?" Experimental Economics 9: 265-279.

Croson, Rachel T.A. (2008). Public Goods Experiments. The New Palgrave Dictionary of Economics. S. N. Durlauf and L. Blume. Houndmills, Palgrave Macmillan. 
Egas, Martijn and Arno Riedl (2008). "The Economics of Altruistic Punishment and the Maintenance of Cooperation." Proceedings of the Royal Society B: Biological Sciences 275(1637): 871-878.

EISEnBerg, TheOdore (1998). "Measuring the Deterrent Effect of Punitive Damages." Georgetown Law Journal 87: 347-358.

EisenberG, TheOdore (2007). "Evidence of the Need for Aggregate Litigation." Journal of Institutional and Theoretical Economics 163: 158-162.

Eisenberg, Theodore and Geoffrey P. Miller (2010). "Attorney Fees and Expenses in Class Action Settlements: 1993-2008." Journal of Empirical Legal Studies 7: 248-281.

Engel, Christoph and Bernd Irlenbusch (2010). Turning the Lab into Jeremy Bentham's Panopticon. The Effect of Punishment on Offenders and Non-Offenders http://ssrn.com/abstract=1555589.

Engel, Christoph and Michael Kurschilgen (2011). "Fairness Ex Ante and Ex Post. Experimentally Testing Ex Post Judicial Intervention into Blockbuster Deals." Journal of Empirical Legal Studies 8: 682-708.

Engelmann, Dirk and Martin Strobel (2004). "Inequality Aversion, Efficiency, and Maximin Preferences in Simple Distribution Experiments." American Economic Review 94: 857-869.

Falk, Armin, ERnst Fehr, et al. (2008). "Testing Theories of Fairness - Intentions Matter." Games and Economic Behavior 62: 287-303.

FAlKinger, Josef, ERnSt Fehr, et al. (2000). "A Simple Mechanism for the Efficient Provision of Public Goods. Experimental Evidence." American Economic Review 90: 247-264.

Fehr, ERnst and Urs Fischbacher (2004). "Third-Party Punishment and Social Norms." Evolution and Human Behavior 25: 63-87.

Fehr, ERnst and Simon GÄChter (2000). "Cooperation and Punishment in Public Goods Experiments." American Economic Review 90: 980-994.

Fehr, ERnst and Simon GÄCHTER (2002). "Altruistic Punishment in Humans." Nature 415: 137 140 .

FISCHBACHER, URS (2007). "z-Tree. Zurich Toolbox for Ready-made Economic Experiments." Experimental Economics 10: 171-178.

Fischbacher, Urs and Simon GÄCHTER (2010). "Social Preferences, Beliefs, and the Dynamics of Free Riding in Public Good Experiments." American Economic Review 100: 541-556. 
Fischbacher, Urs, Simon Gächter, et al. (2001). "Are People Conditionally Cooperative? Evidence from a Public Goods Experiment." Economics Letters 71: 397-404.

Frakes, Michael and Matthew Harding (2009). "The Deterrent Effect of Death Penalty Eligibility. Evidence from the Adoption of Child Murder Eligibility Factors." American Law \& Economics Review 11: 451-497.

GÄCHTER, SimON and ELKE RENNER (2010). "The Effects of (Incentivized) Belief Elicitation in Public Goods Experiments." Experimental Economics 13: 364-377.

Galbiati, Roberto and Pietro Vertova (2008). "Law and Behaviours in Social Dilemmas. Testing the Effect of Obligations on Commitment." Games and Economic Behavior 64: 146-170.

Grechenig, Kristoffel, Andreas Nicklisch, et al. (2010). "Punishment Despite Reasonable Doubt. A Public Goods Experiment with Sanctions Under Uncertainty." Journal of Empirical Legal Studies 7(4): 847-867.

GreINER, BEN (2004). An Online Recruiting System for Economic Experiments. Forschung und wissenschaftliches Rechnen 2003. K. Kremer and V. Macho. Göttingen: 79-93.

Güth, Werner, Hartmut Kliemt, et al. (2007). "On the Co-Evolution of Retribution and Trustworthiness. An (Indirect) Evolutionary and Experimental Analysis." Journal of Institutional and Theoretical Economics 163: 143-157.

HARdin, GarRetT (1968). "The Tragedy of the Commons." Science 162: 1243-1248.

Heckathorn, Douglas D. (1989). "Collective Action and the Second-Order Free-Rider Problem." Rationality and Society 1: 78-100.

Hensler, Deborah R., M.Susan Marquis, et al. (1991). Compensation for Accidental Injuries in the United States, RAND Corporation.

Hermalin, Benjamin E., Avery W. Katz, et al. (2007). Contract Law. Handbook of Law and Economics. A. M. Polinsky and S. Shavell. Amsterdam, North Holland. 1: 3-138.

Herrmann, Benedikt, Christian ThÖnI, et al. (2008). "Antisocial Punishment Across Societies." Science 319: 1362-1367.

Janssen, Marco A., John M. Anderies, et al. (2011). "Coordination and Cooperation in Asymmetric Commons Dilemmas." Experimental Economics 14: 547-566.

Kohn, Linda T., Janet M. Corrigan, et al. (2000). To Err is Human. Building a Safer Health System, National Academy Press. 
Landrigan, Christopher P., Gareth J. Parry, et al. (2010). "Temporal Trends in Rates of Patient Harm Resulting from Medical Care." New England Journal of Medicine 363(22): 2124-2134.

LAw ReForm COMmission OF IREland (1998). Consultation Paper on Aggravated, Exemplary and Restitutionary Damages

http://www.lawreform.ie/_fileupload/consultation\%20papers/cpAggravatedDamages.htm.

Ledyard, John O. (1995). Public Goods. A Survey of Experimental Research. The Handbook of Experimental Economics. J. H. Kagel and A. E. Roth. Princeton, NJ, Princeton University Press: 111-194.

Mello, Michelle M., David M. Studdert, et al. (2007). "Who Pays for Medical Errors? An Analysis of Adverse Event Costs, the Medical Liability System, and Incentives for Patient Safety Improvement." Journal of Empirical Legal Studies 4(4): 835-860.

Nikiforakis, Nikos S. and Hans-Theo Normann (2008). "A Comparative Statics Analysis of Punishment in Public Good Experiments." Experimental Economics 11: 358-369.

Nikiforakis, Nikos S., Hans-Theo Normann, et al. (2010). "Asymmetric Enforcement of Cooperation in a Social Dilemma." Southern Economic Journal 76(3): 638-659.

O'Gorman, Rick O., Joseph Henrich, et al. (2009). "Constraining Free Riding in Public Goods Games. Designated Solitary Punishers can Sustain Human Cooperation." Proceedings of the Royal Society B: Biological Sciences 276(1655): 323-329.

Ostrom, Elinor, James M. WALKer, et al. (1992). "Covenants with and without Sword. SelfGovernance is Possible." American Political Science Review 40: 309-317.

Page, Talbot, Louis Putterman, et al. (2005). "Voluntary Association in Public Goods Experiments. Reciprocity, Mimicry and Efficiency." Economic Journal 115: 1032-1053.

Plato-Shanar, Ruth (2007). "Israel: The New Law on Class Actions." J.B.L.: 527-540.

Rondeau, Daniel, Gregory L. Poe, et al. (2005). "VCM or PPM? A Comparison of the Performance of two Voluntary Public Goods Mechanisms." Journal of Public Economics 89(8): 1581-1592.

Rondeau, Daniel, William D. Schulze, et al. (1999). "Voluntary Revelation of the Demand for Public Goods Using a Provision Point Mechanism." Journal of Public Economics 72(3): 455-470.

Rubin, Paul H. and Joanna M. Shepherd (2006). "Tort Reform and Accidental Deaths." Journal of Law and Economics 50: 221-238. 
Schwartz, GARY (1994). "Reality in the Economics of Tort Law. Does Tort Law Really Deter?" UCLA Law Review 42: 377-444.

Sefton, Martin, Robert Shupp, et al. (2007). "The Effect of Rewards and Sanctions in Provision of Public Goods." Economic Inquiry 45(4): 671-690.

Shavell, SteVen (1984). "Liability for Harm Versus Regulation of Safety." Journal of Legal Studies 13: 357-374.

Shavell, Steven (2007). Economic Analysis of Accident Law, Harvard Univ Pr.

Sloan, Frank A., Emily M. Stout, et al. (2000). Drinkers, Drivers, and Bartenders. Balancing Private Choices and Public Accountability, University of Chicago Press.

SousA, Sergio (2010). Cooperation and Punishment under Uncertain Enforcement http://ideas.repec.org/p/cdx/dpaper/2010-06.html.

Tyran, JeAn-Robert and Lars P. Feld (2006). "Achieving Compliance when Legal Sanctions are Non-Deterrent." Scandinavian Journal of Economics 108: 135-156.

VISCUSI, W. KIP (1998). "The Social Costs of Punitive Damages Against Corporations in Environmental and Safety Torts." Georgetown Law Journal 87: 285-345.

YAMAgishi, Toshio (1986). "The Provision of a Sanctioning System as a Public Good." Journal of Personality and Social Psychology 51: 110-116.

Zelmer, JenNifer (2003). "Linear Public Goods. A Meta-Analysis." Experimental Economics 6: 299-310. 


\section{$\underline{\text { Instructions }}$}

Welcome to our experiment. Please remain quiet and do not talk to the other participants during the experiment. Should you have any questions, please let us know by raising your hand. We will then come to you and answer your questions personally.

At the end of the experiment, your earnings, resulting from the decisions you have made during the experiment, will be paid to you in cash. In addition, you will receive $4 €$ for taking part in the experiment, regardless of the decisions that you and the other participants assigned to you make. We will explain the details of how your payoff is calculated for each separate part of the experiment. In the first part of the experiment, which is explained in the following, we mention the term Taler. At the end of the experiment, each Taler will be converted into 1 Eurocent $(0.01 €)$.

At the beginning of this part of the experiment, participants are randomly divided into groups of four. You and three other participants will therefore make up a group. The group remains unchanged during the entire part of this experiment. The experiment consists of 30 periods. Each period consists of 2 stages.

\section{Stage 1}

At the beginning of each of the 30 periods, each participant receives 20 Taler. In the following, we refer to this sum as the "endowment". In Stage 1, your task is to decide how to use this endowment. You have to decide how many of the 20 Taler (any number between 0 und 20) you wish to contribute to a project, and how many Taler you wish to keep for yourself. We will explain the consequences of this decision later on.

As soon as all group members have decided on their contributions to the project, we will inform you about each group member's contribution, your income from the project, and your payoff for this period. In every period, your payoff is calculated by means of the following simple formula; if you have any difficulty understanding it, please ask us.

$\begin{array}{ll}\text { Payoff } & \begin{array}{l}\text { Endowment of } 20 \\ \text { Taler }\end{array} \\ \text { project } & \begin{array}{l}\text { Your contribution to the } \\ \text { project }\end{array}\end{array} \quad \begin{aligned} & 0.4 * \text { all contributions to the } \\ & \text { project }\end{aligned}$

This formula shows that your payoff for Stage 1 consists of two parts:

1) the Taler that you have kept for yourself (endowment - contribution)

2) the income from the project, which is made up of 40 per cent of the group's entire contributions.

The payoff of each group member is calculated in the same way. Each group member hence receives the same payoff from the project. If you assume that the sum of all group members' contributions is 60 Taler, in that case each member is given a payoff of $0.4 * 60=24$ Taler. If the sum of all group members' contributions is 9 Taler, then each group member is paid $0.4 * 9=3.6$ Taler.

You always have the option of keeping Taler for yourself, or else of contributing to the project. Every Taler that you keep increases your income by one Taler at the end of the period. If instead you contribute this Taler to the project, then the contributions to the project increase by one Taler. Your income from the project increases by $0.4 * 1=0.4$ Taler. The other group members' income, however, also increases by 0.4 Taler each, so that the total group income from the project is 1.6 Taler. Your contribution to the project hence also increases the other group members' income. On the other hand, you also earn something from every Taler contributed to the project by the other members. For every Taler contributed by another group member, you receive 0.4 Taler. 


\section{Stage 2 [compensatory, compensation only]}

In Stage 2, you are told how much each individual member of the group has contributed to the project in Stage 1. In each period, one member is randomly chosen (we refer to this player as the "active player"). The active player, and only this player, is given the possibility to react to the information about the other three members' contributions. <The active player can transfer income from each of the other group members to his own account. The active player is free to choose the group members whose money he wishes to take.

However, this permission has limits. The active player may take from any other group member at most a sum that would lead to the active player receiving the period income he would have had if the other member had contributed as much as the active player did. In the following paragraph, we provide an example of how the maximum limit is calculated. You do not need to perform these calculations yourself during the experiment. For each of the remaining group members, you will be given a maximum limit on your screen:

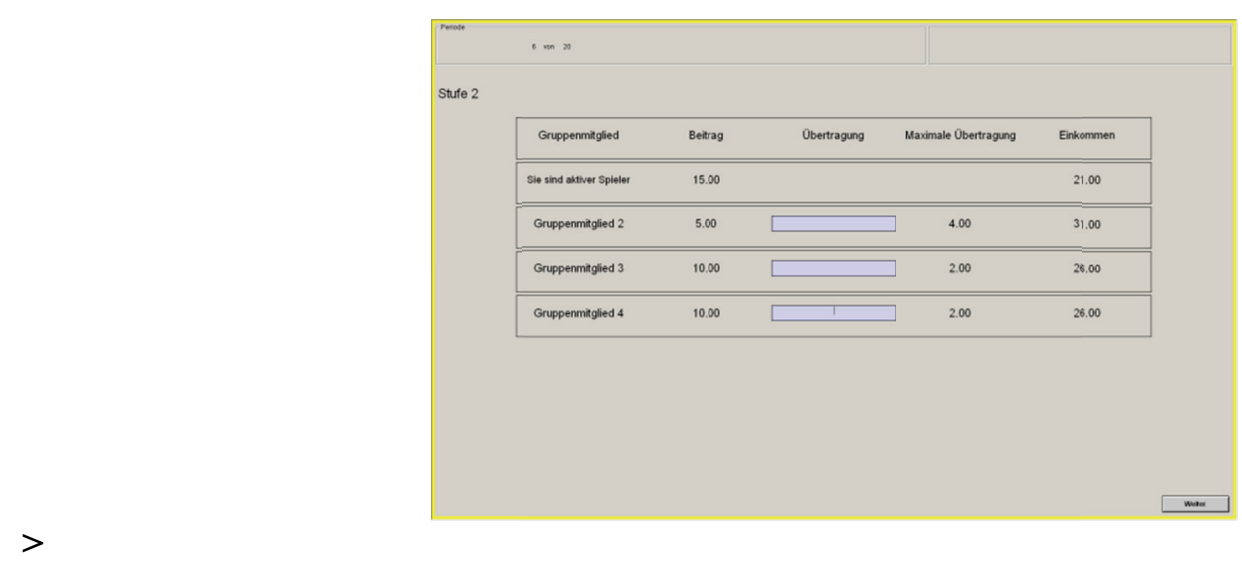

Now, how are these maximum limits calculated? In the second stage, you are the active player. You had contributed 15 Taler. Another member of your group had contributed 5 Taler. The two remaining members had each contributed 10 Taler. Hence your payment is 20 [endowment] -15 [contribution] +0.4 * $(15+10+10+5)$ [income from the project] $=21$ Taler. If all other group members had also contributed 15 Taler, then your payoff would have consisted of $20-15+0.4 * 4 * 15=29$ Taler. The difference between payoffs is therefore 8 Taler. In the following graphical representation, you will see the result of Stage 1 on the left-hand side. In the graph on the right, you will see in red the difference between the actual payoff of the active player and the payoff he could have received. The turquoise areas show in which way the passive players contributed to this difference.
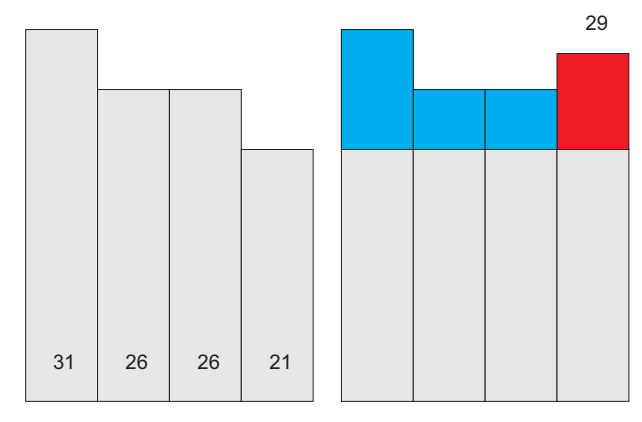

The maximum sum that the active player can transfer mirrors these differences. The upper limit is proportional to the difference between his own contribution and this player's contribution. Continuing the last graphical representation, we can depict the situation as follows: 


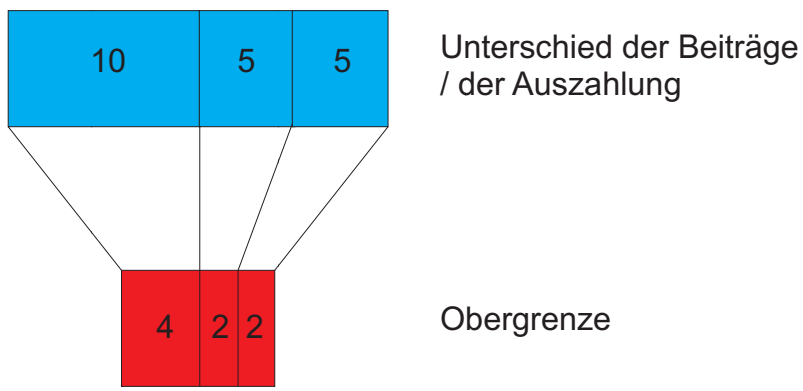

Please note that the active player may not keep money belonging to other players if his own payoff would have been lower or the same, had all other group members contributed the same amount as he did; further, note that he is only allowed to keep money belonging to other group members if they have contributed less to the project than he has.

Please note also that, in each period, each group member receives a random number between 1 and 4 . From one period to the next, the group members are hence not identified. You will therefore not know which group members had the opportunity in the past to keep money for themselves. You will only know whether income has been transferred, and how much has been transferred, if the active player has kept a part of your period income.

\section{[compensatory with forfeit option replace text in $<>$ with]}

The active player has two possibilities: either he can transfer income from any of the other group members to himself, or else he can withdraw income, the consequence of that action being that the money can no longer be used. The active player is free to choose the group members whose money he wishes to take.

However, this permission has limits. The active player may take from any other group member at most a sum that would lead to the active player receiving the period income he would have had if the other member had contributed as much as the active player did. In the following paragraph, we provide an example of how the maximum limit is calculated. You do not need to perform these calculations yourself during the experiment. For each of the remaining group members, you will be given a maximum limit on your screen:

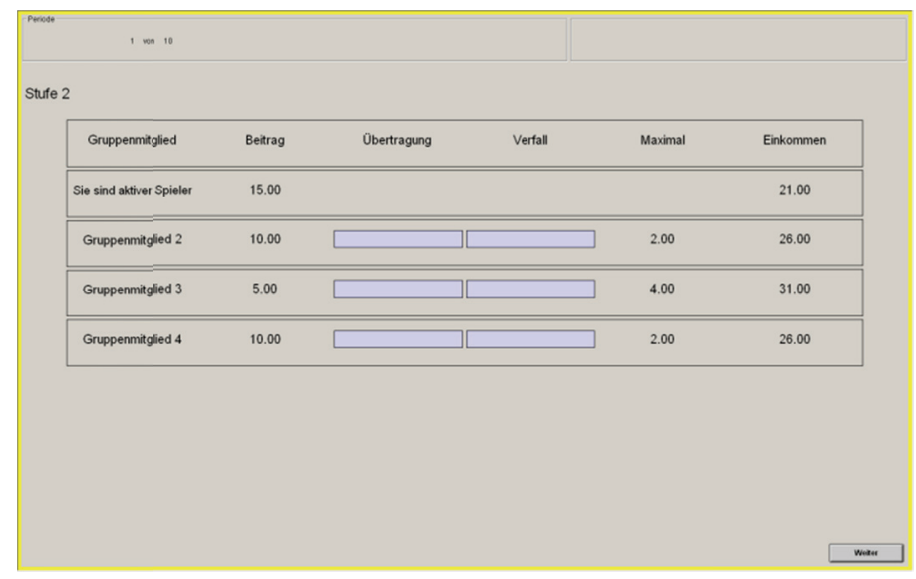

\section{Stage 2 [class action, compensation only]}

In Stage 2, you are told how much each individual member of the group has contributed to the project in Stage 1. In each period, one member is randomly chosen (we refer to this player as the "active player"). The active player, and only this player, is given the possibility to react to the information about the other three members' contributions. < The active player can transfer income from each of the other group 
members to himself. The active player is free to choose the group members whose money he wishes to take.

However, this permission has limits. The active player may only take from any other group member the difference between the actual income of all group members and the income as such that they would have had if everyone had contributed as much as he himself contributed. In the following paragraph, we provide an example of how the maximum limit is calculated. You do not need to perform these calculations yourself during the experiment. For each of the remaining group members, you will be given a maximum limit on your screen:

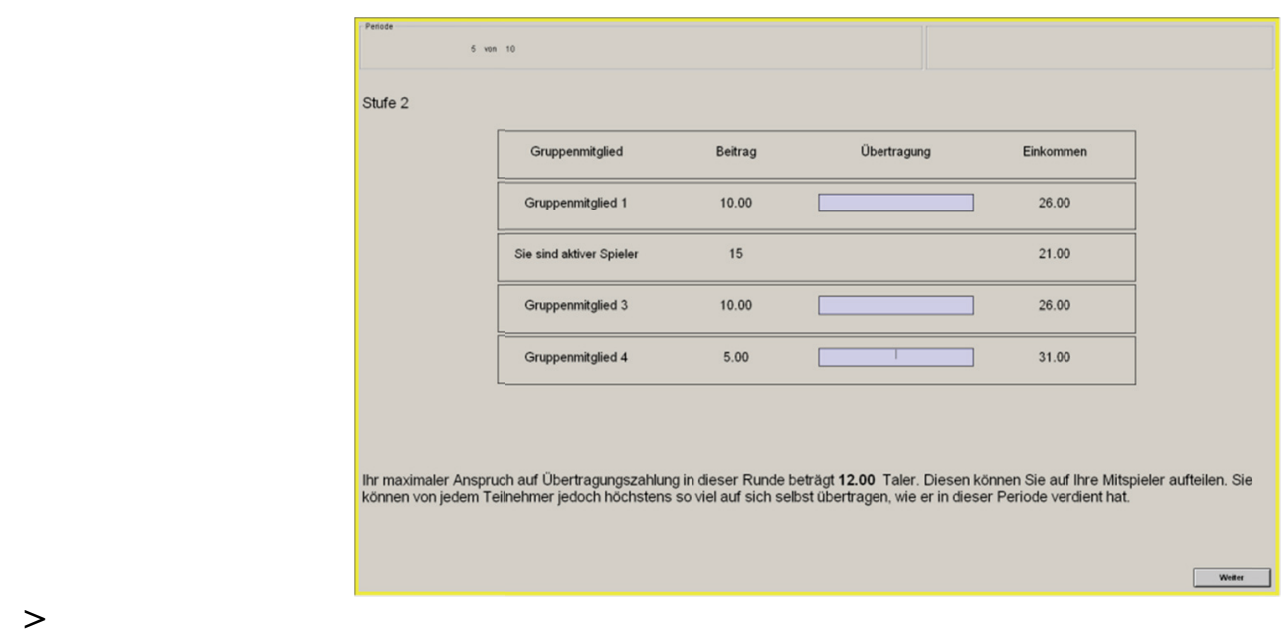

Now, how is this maximum limit calculated? In the second stage, you are the active player. You had contributed 15 Taler. Another member of your group had contributed 5 Taler. The two remaining members had each contributed 10 Taler. Hence your payment is 20 [endowment] -15 [contribution] $+0.4 *(15+$ $10+10+5$ ) [income from the project] $=21$ Taler. Similarly, the other group members have received payments of 26, 26, and 31 Taler. The entire group payoff is therefore 104 Taler. If all other group members had also contributed 15 Taler, then the entire contribution to the project would have been $4 * 15=60$ Taler, each group member earning 29 Taler. The entire group payoff would then have been 116 Taler. Hence the maximum limit is $116-104=12$ Taler. In the following graphical representation, you will see the result of Stage 1 on the left-hand side. On the right, you will see, in red, the sum of the differences between 29 and the actual income of all group members who have earned less than 29 . The turquoise area is subtracted from that, in other words the amount by which the earnings of player 1 have exceeded 29.
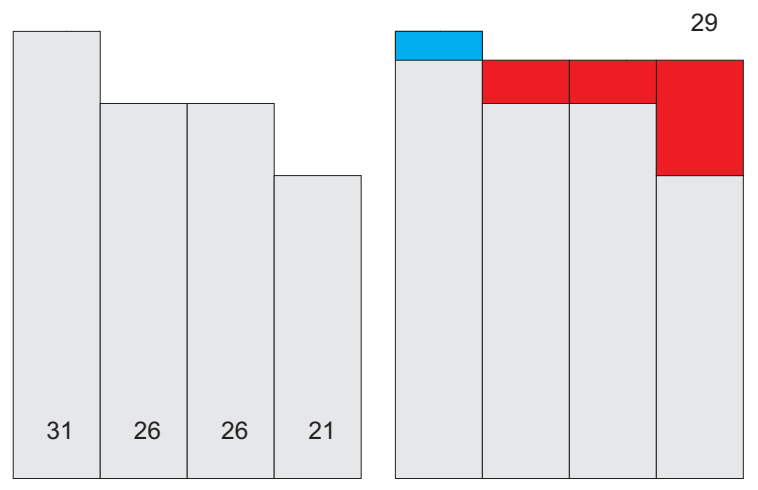

Please note that the active player may not keep money belonging to other players if his own payoff would have been lower or the same, had all other group members contributed the same amount as he did; further, note that he is only allowed to keep money belonging to other group members if they have contributed less to the project than he has. As a rule, the active player is free to take the maximum sum from a single group member or from several others as he sees fit. However, he may take from each player at most what that player has actually earned in this period. 
Please note also that, in each period, each group member receives a random number between 1 and 4 . From one period to the next, the group members are hence not identified. You will therefore not know which group members had the opportunity in the past to keep money for themselves. You will only know whether income has been transferred, and how much has been transferred, if the active player has kept a part of your period income.

\section{[class action with forfeit option replace text in $<>$ with]}

The active player has two possibilities: either he can transfer income from any of the other group members to himself, or else he can withdraw income, the consequence of that action being that the money can no longer be used. The active player is free to choose the group members whose money he wishes to take.

However, this permission has limits. The active player may only take from any other group member the difference between the actual income of all group members and the income as such that they would have had if everyone had contributed as much as he himself contributed. In the following paragraph, we provide an example of how the maximum limit is calculated. You do not need to perform these calculations yourself during the experiment. For each of the remaining group members, you will be given a maximum limit on your screen:

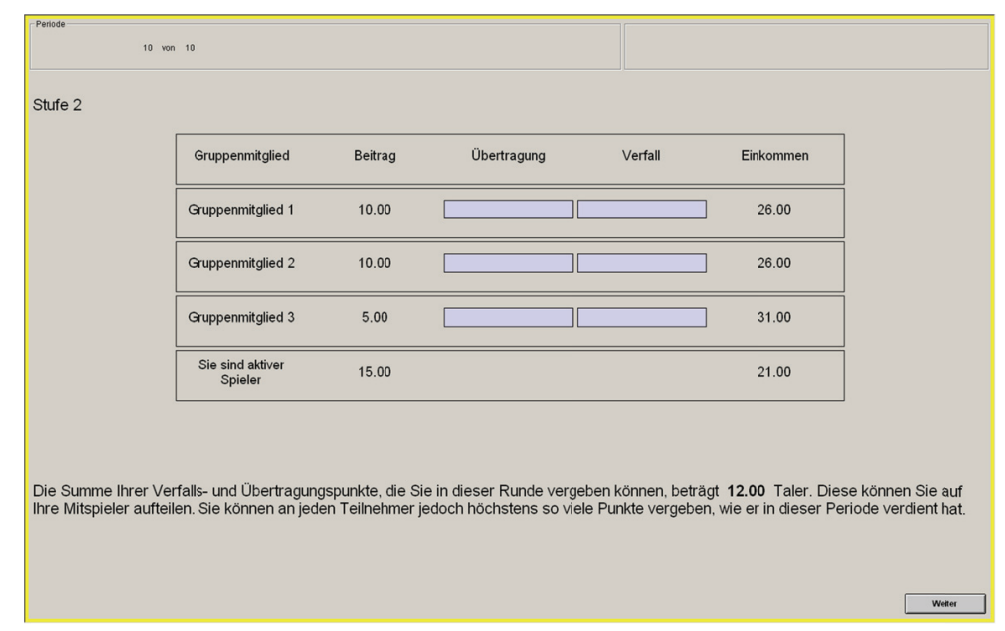

\section{stage 2 [punitive, compensation only]}

In Stage 2, you are told how much each individual member of the group has contributed to the project in Stage 1. In each period, one member is randomly chosen (we refer to this player as the "active player"). The active player, and only this player, is given the possibility to react to the information about the other three members' contributions. < The active player can transfer income from each of the other group members to his own account. The active player is free to choose the group members whose money he wishes to take.

However, this permission has limits. The active player may take from any other group member at most the amount that this player has earned in this period. For each of the remaining group members, you will be given a maximum limit on your screen: 


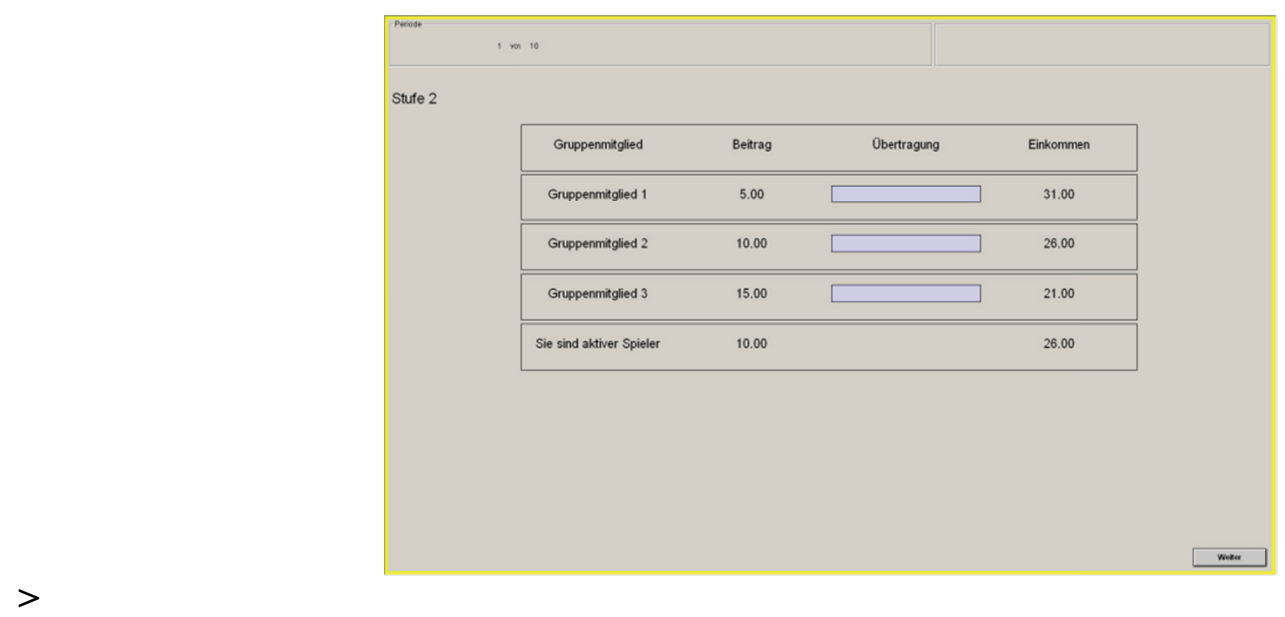

Please note also that, in each period, each group member receives a random number between 1 and 4 . From one period to the next, the group members are hence not identified. You will therefore not know which group members had the opportunity in the past to keep money for themselves. You will only know whether income has been transferred, and how much has been transferred, if the active player has kept a part of your period income.

\section{[punitive with forfeit option replace text in $<>$ with]}

The active player has two possibilities: either he can transfer income from any of the other group members to himself, or else he can withdraw income, the consequence of that action being that the money can no longer be used. The active player is free to choose the group members whose money he wishes to take.

However, this permission has limits. The active player may take from any other group member at most the amount that this player has earned in this period. For each of the remaining group members, you will be given a maximum limit on your screen:

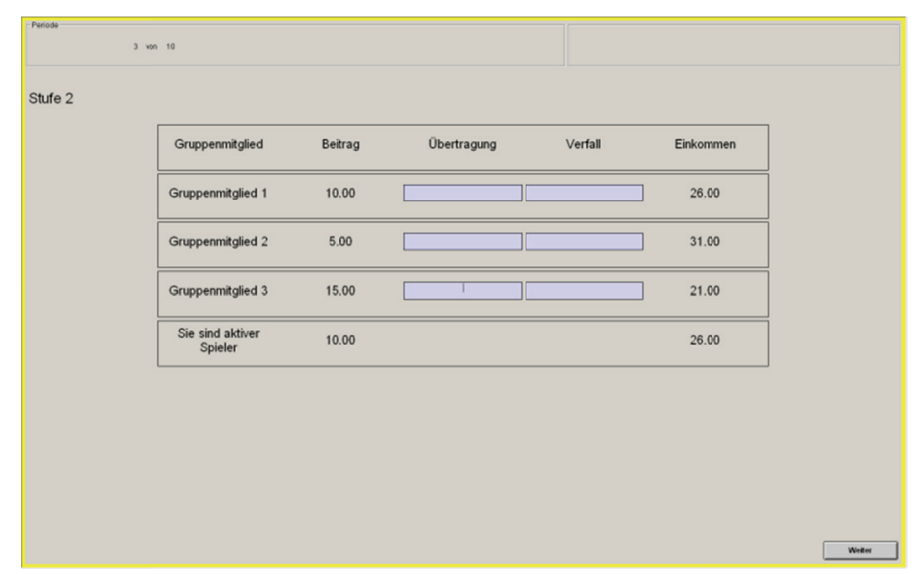

